\title{
Hadron Therapy Achievements and Challenges: The CNAO Experience
}

\author{
Sandro Rossi (D)
}

check for

Citation: Rossi, S. Hadron Therapy Achievements and Challenges: The CNAO Experience. Physics 2022, 4, 229-257. https://doi.org/10.3390/ physics4010017

Received: 2 December 2021

Accepted: 14 February 2022

Published: 22 February 2022

Publisher's Note: MDPI stays neutral with regard to jurisdictional claims in published maps and institutional affiliations.

Copyright: (c) 2022 by the author. Licensee MDPI, Basel, Switzerland. This article is an open access article distributed under the terms and conditions of the Creative Commons Attribution (CC BY) license (https:// creativecommons.org/licenses/by/ $4.0 /)$.
CNAO Foundation, Strada Campeggi 53, 27100 Pavia, Italy; sandro.rossi@cnao.it

\begin{abstract}
Protons and carbon ions (hadrons) have useful properties for the treatments of patients affected by oncological pathologies. They are more precise than conventional X-rays and possess radiobiological characteristics suited for treating radio-resistant or inoperable tumours. This paper gives an overview of the status of hadron therapy around the world. It focusses on the Italian National Centre for Oncological Hadron therapy (CNAO), introducing operation procedures, system performance, expansion projects, methodologies and modelling to build individualized treatments. There is growing evidence that supports safety and effectiveness of hadron therapy for a variety of clinical situations. However, there is still a lack of high-level evidence directly comparing hadron therapy with modern conventional radiotherapy techniques. The results give an overview of preclinical and clinical research studies and of the treatments of 3700 patients performed at CNAO. The success and development of hadron therapy is strongly associated with the creation of networks among hadron therapy facilities, clinics, universities and research institutions. These networks guarantee the growth of cultural knowledge on hadron therapy, favour the efficient recruitment of patients and present available competences for R\&D (Research and Development) programmes.
\end{abstract}

Keywords: hadron therapy; carbon ions therapy; proton therapy; medical synchrotron; gantry

\section{Introduction}

"Hadron therapy", a word that has entered the vocabulary of medicine, indicates the therapeutic use of "hadrons", nuclear particles known in the past only in physics research centres. Hadrons derive their name from the Greek 'hadrós' ('strong'), which identifies the force with which their main constituents, the quarks, interact (coined by Soviet physicist Lev B. Okun). The hadrons used today in hadron therapy centres all over the world are protons, containing three quarks, and carbon ions-made of six protons and six neutrons and thus containing 36 constituent quarks-and very recently also helium ions [1], composed of two protons and two neutrons, hence containing 12 quarks. The treatments with carbon ion beams are often referred to as CIRT, which stands for Carbon Ions Radiation Therapy. In particle physics, carbon ions are relatively light particles and therefore they are called light ions. The convention is different in radiotherapy where carbon ions are often referred to as heavy particles to distinguish them from protons.

\section{Rationale and Diffusion of Hadron Therapy in the World}

Charged atomic nuclei, such as protons or carbon ions, have a completely different energy deposition curve with respect to X-rays, showing the characteristic Bragg peak at the end of their path in tissues (Figure 1) [2].

The energy deposited per gram of matter (i.e., the 'dose') is low when the hadron beam enters the body and is mainly concentrated at the end of the range. The so-called Bragg peak is rather narrow (few millimetres) and to cover the full longitudinal extension of the tumour a superposition of Bragg peaks with different heights and depths is necessary, creating a Spread Out Bragg Peak (SOBP). The use of a focused beam of millimetric transverse dimensions-displaced by scanning magnets in the plane perpendicular to the 
beam direction-allows the painting of slices of a tumour. The combination of longitudinal (varying the beam energy) and transversal (by magnetic scanning) displacement of the beam creates an almost ideal coverage of the tumour volume and a low radiation dose deposited outside. Carbon ions are more precise than protons because, due to the larger mass, they have a reduced longitudinal range variation (straggling) and a smaller lateral scattering thus a sharper lateral penumbra [3].

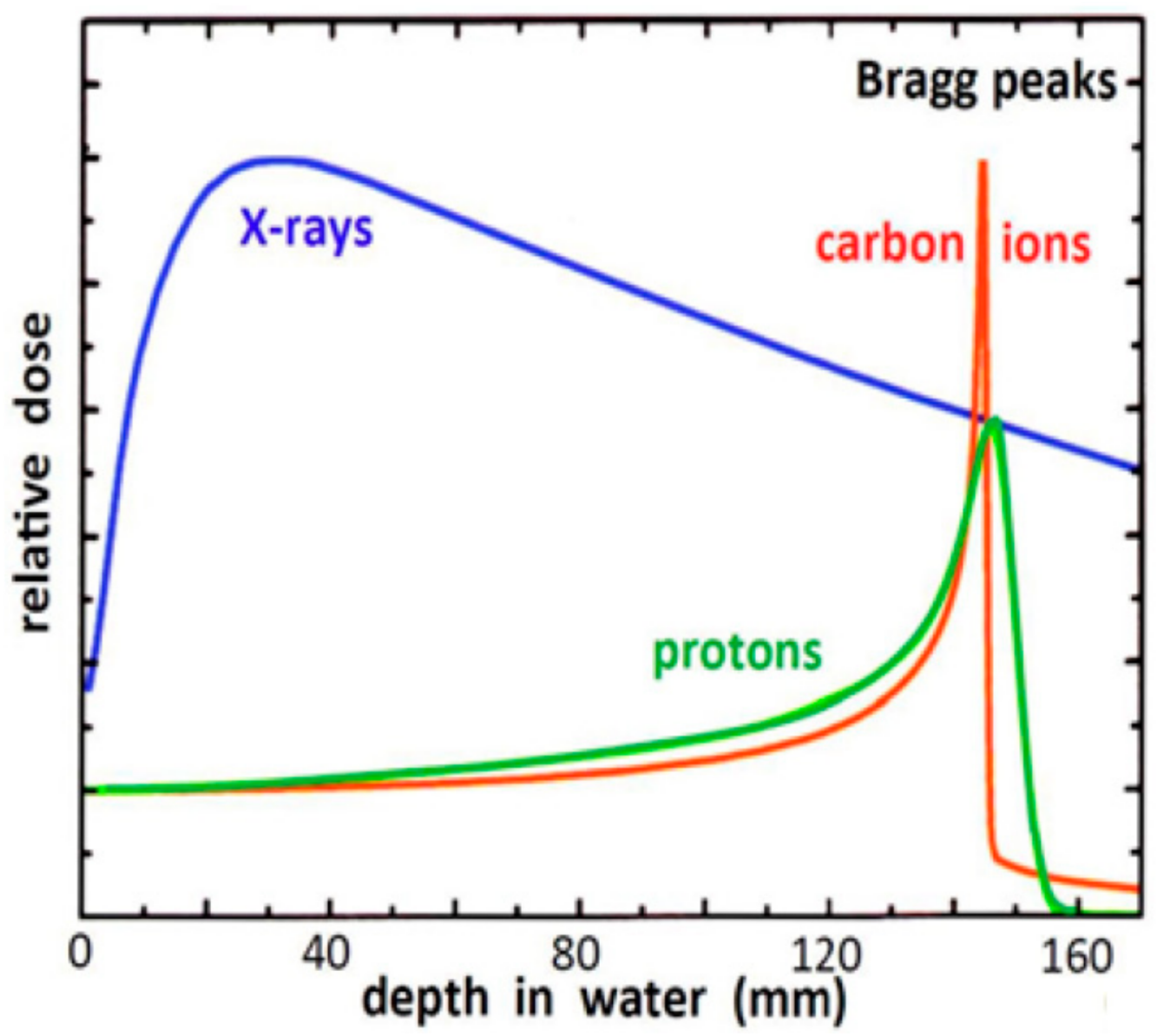

Figure 1. Energy deposition in water by X-ray photons, protons and carbon ions. The energy of the $\mathrm{X}$-rays is $21 \mathrm{MeV}$. The energy of the two particles is selected to provide the same range: $148 \mathrm{MeV} / \mathrm{u}$ for protons and $270 \mathrm{MeV} / \mathrm{u}$ for carbon ions [2].

Carbon ions have a different action on the cells of the traversed organs with respect to protons or X-rays. At the end of their range the energy deposition per unit length (the 'Linear Energy Transfer' or LET) is producing a larger number of irreparable double strand DNA (deoxyribonucleic acid) breaks with a much higher probability of cell killing [4]. This action is usually expressed in terms of the relative biological effectiveness (RBE), which is defined as the ratio of the photon dose and the dose of the particle radiation leading to the same biological effect. RBE of carbon ions on the tumour can be as high as 3, thus allowing the delivery of a higher biological dose in the tumour target with respect to photons and protons, while keeping the same 'biological' dose in the surrounding normal tissues, or the same dose in the tumour and reduced doses and damages to the normal tissues. Moreover, the higher fraction of clustered DNA lesions produced by ions, which cannot be repaired by the usual cellular mechanisms, is processed via alternative end-joining mechanisms [5] and opens the way to the use of smart radio-sensitizers that makes tumour cells more sensitive to ion therapy. Another quantitative advantage is that ions have a reduced Oxygen Enhancement Ratio (OER) and are hence less dependent on the availability of oxygen in the tumour tissue. This means that they are effective in the treatment of hypoxia-related 
radio-resistant tumours, so that they can eradicate tumours that are resistant to $X$-ray and proton therapy [6-9]. The latter represent $1-3 \%$ of all patients treated with $X$-rays, for whom CIRT is the only effective radiation treatment.

Recent data also point out even more significant biological effects of ion therapy, including reduced angiogenesis $[10,11]$, reduced metastasis $[12,13]$ and increased immune response following exposure to light ions [14]. This implies that ion therapy can be used to enhance the effectiveness of cancer immunotherapy.

The idea of using protons to treat tumours dates back to 1946, when the American scientist Bob Wilson [15] understood their potential due to the physical characteristics of the deposited dose. It is important to note that, until the end of the 1980s, patients were irradiated at accelerators built for nuclear and sub-nuclear physics research and adapted to radiotherapy, with all the associated drawbacks. At the beginnings of the 1990s, the era of modern hadron therapy finally began, with centres dedicated exclusively to clinical activity. The first proton therapy facility is the Loma Linda University Medical Centre, in California [16]. Three rooms are equipped with rotating magnetic systems (isocentric 'gantries') of about ten meters diameter and a mass of about 100 tons that allow-for the first time-to vary the direction of incidence of the proton beam on the patient, as usually happens in conventional radiotherapy. In Japan, in June 1994, the first patient was treated with a carbon ion beam of about $4000 \mathrm{MeV}$ at the Heavy Ion Medical Accelerator Centre in Chiba [17]. In this case, the beams are fixed, horizontal and vertical, and they serve three treatment rooms. A few years ago, the centre was upgraded with the addition of new treatment rooms, one of which equipped with a carbon ion gantry made of superconducting magnets.

The National Centre for Oncological Hadronterapy (CNAO) operates in Pave, Italy. Patient treatments started in 2011 and both protons and carbon ions are routinely delivered in three treatment rooms. Each room has a horizontal beam and room 2 has an additional vertical beamline. A fourth room, with a horizontal beamline, is fully devoted to research. Figure 2 shows the hospital facility and the synchrotron accelerator.

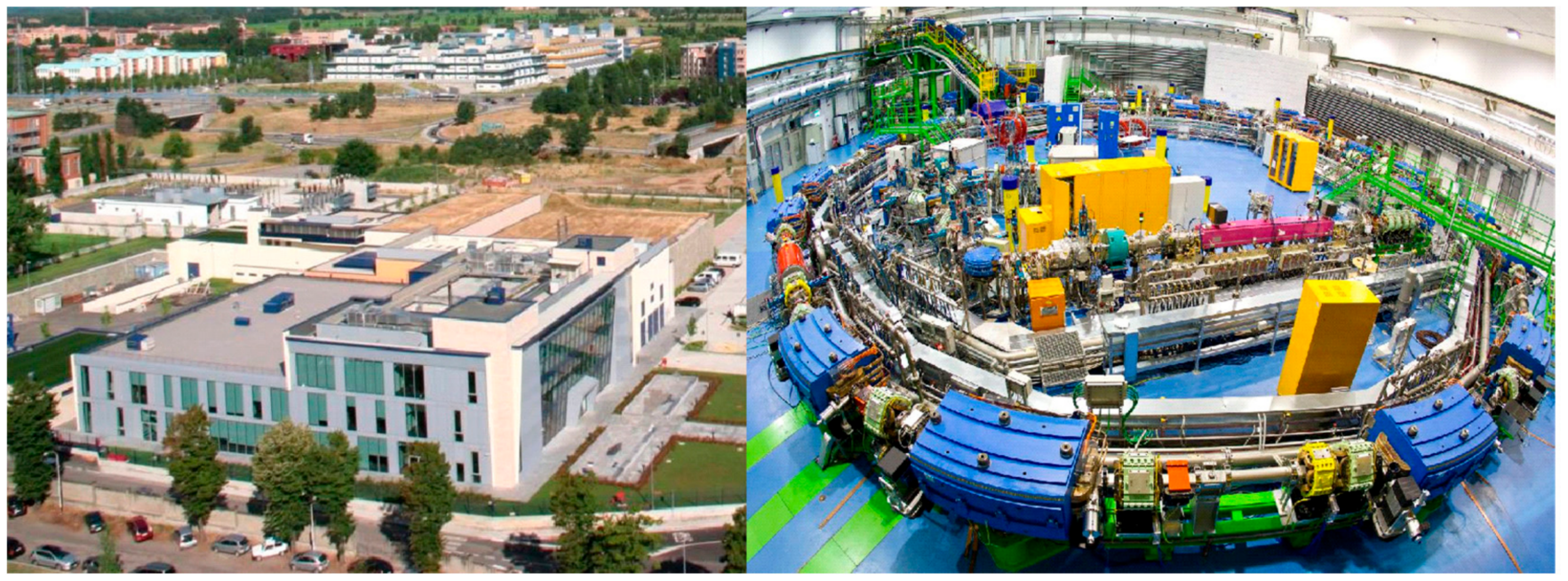

Figure 2. Left: in front the Centre for Oncological Hadron therapy (CNAO) hospital building, in the back the power station and the roof of the synchrotron vault. Right: view of the synchrotron and of the beam transport lines.

The growth and diffusion of hadron therapy requires many efforts and international collaborations. To this end, the European Network for Light Ion Hadron Therapy (ENLIGHT) [18] continues to play a central role in the development and diffusion of hadron therapy and in meeting the needs of the community for the education of specialised professionals.

More recently, the four European hadron therapy facilities offering CIRT, together with 18 Partners from 14 European countries, launched a four-year collaboration project 
named HITRIplus (Heavy Ion Therapy Research Integration plus), that has been approved in the framework of the Horizon 2020 research and innovation programme (agreement GA N. 101008548).

HITRIplus is a multidisciplinary collaborative project, aiming to open the existing facilities to the clinical and research communities, to integrate and advance biophysics and medical research in cancer treatment with ions and, in parallel, to develop innovative technologies for the next generation of centres.

Currently, proton therapy and CIRT are expanding worldwide with 94 proton therapy centres, as reported by the Particle Therapy Group website [19]; the synchrotrons of twelve centres perform CIRT with maximum ion energy of about $400 \mathrm{MeV} /$ nucleon, which corresponds to $27 \mathrm{~cm}$ range in water. Proton therapy centres are mainly located in the United States (41 centres), Europe (19 centres), Japan (17 centres) and the UK (5 centres). Carbon ion centres are located in Japan (6 centres), Europe (4 centres) and China ( 2 centres). Four European clinical centres (CNAO, Heidelberg Ion Therapy Center-HIT, MedAustron and Marburger Ionenstrahl-Therapiezentrum-MIT), one Japanese and one Chinese centre produce both carbon ions and protons, thus they are called 'multi-particle centres'. There are at present 32 proton centres and 6 carbon ions centres under construction. In addition, 26 new proton facilities and 2 carbon ions centres, including the first one in USA, are in the planning phase.

The overall number of patients treated with protons has reached 290,000 and grows by more than 35,000 per year. More than 40,000 patients have been irradiated with CIRT worldwide.

\section{Experimental Part}

The configurations of all the running facilities for CIRT are similar. Typically, they feature:

- $\quad$ two (or more) ion sources;

- $\quad$ an injector linac;

- a room-temperature synchrotron;

- $\quad$ a high-energy beam transport line, made of magnets that steer and focus the beam; one or more horizontal beamlines and at least one vertical beamline, equipped with instruments that actively 'paint' the tumour and produce the dose distributions required by the Treatment Planning System;

- $\quad$ in the case of HIT (Heidelberg) and NIRS (Chiba), a carbon ion gantry also rotates the beam around the patient couch;

- $\quad$ robotic patient positioning devices and in-room imaging verification systems.

Accelerator science and technology have made an impressive progress in the last two decades, as demonstrated by the successes of large-scale accelerator projects-such as the Large Hadron Collider (LHC) at the European Organization for Nuclear Research (CERN)and by the wide number of modern accelerator-based systems built worldwide for basic or applied science, industry and medicine. Applying some of the recent developments in accelerator technology to a new generation of ion therapy and research accelerators is the goal of a study group established in 2020 at CERN called NIMMS (Next Ion Medical Machine Study) [20]. New superconducting (SC) magnets, new injector linacs and novel lattice designs are also the objective of EU funded research projects such as HITRIplus and IFAST [21].

The accelerator represents a large fraction of the construction and operation costs of an ion therapy facility. Present synchrotron rings use warm magnets and the circumferences range roughly between 65 and $85 \mathrm{~m}$. New technologies aim to reduce ring dimensions by a factor of 2, and, in Japan, even more extreme and compact designs are being studied [22].

All CIRT facilities in the world use fixed beamlines, horizontal, vertical and oblique $45^{\circ}$. Patients are treated with carbon ion gantries only in Heidelberg, at the HIT centre, and in China at HIMAC. The first one in the world at HIT is $25 \mathrm{~m}$ long, $13 \mathrm{~m}$ in diameter and weighs over 600 tons. This is an isocentric gantry and the patient's body lies on the rotation axis; the gantry rotates by 360 degrees and has scanning magnets upstream the last $90^{\circ}$ 
bending. The gantry in HIMAC is also isocentric. It uses superconducting magnets, has a length of $13 \mathrm{~m}$ and weighs about 300 tons. The maximum magnetic field achieved by the ten superconducting magnets, which operate at cryogenic temperatures of just a few degrees Kelvin, is $2.88 \mathrm{~T}$.

Due to the characteristics of the existing gantries, it seems worth investing resources in the research and development of a new gantry for carbon ions. An ideal ion gantry should be much lighter than the current ones (less than 100 tons) and require much less energy consumption. It should also have a large irradiation field to be able to treat extensive neoplasms; it should be compatible with an active three-dimensional distribution of the beams, possibly particularly fast, in order to better manage the problem of organ motion. Its capital cost should be limited and convenient, to make its acquisition appealing for all the carbon ion facilities.

The CNAO Foundation, together with CERN, INFN (National Institute for Nuclear Physics, Italy) and MedAustron, has recently launched an international collaboration to study a gantry design for carbon ions, optimized for clinical requirements. One solution, developed from an initial idea of the TERA Foundation $[23,24]$, is shown in Figure 3. The introduction of new technologies in the manufacture of magnets, the adoption of new geometries and structures, the implementation of simple and high-performance mechanical solutions and the integration of patient irradiation and tumour imaging systems are the lines of development followed to converge towards an innovative and effective solution.

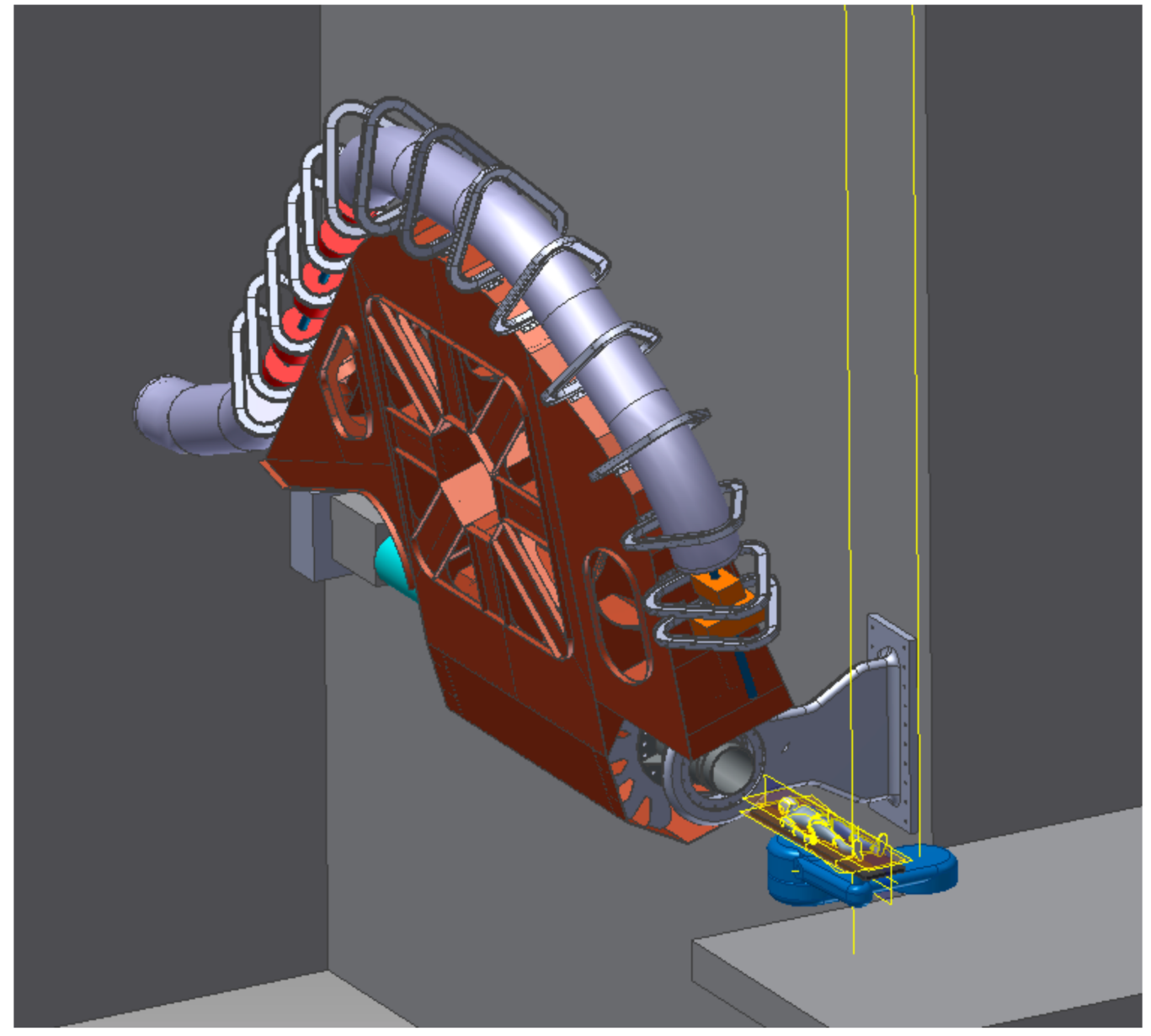

Figure 3. Schematic image of a compact gantry, with $180^{\circ}$ rotation, designed within the collaboration activity performed by CERN-CNAO-INFN-MedAustron working group. 


\subsection{The National Centre for Oncological Hadron Therapy (CNAO)}

$\mathrm{CNAO}$ is one of the four centres in Europe, and six worldwide, offering treatment of tumours with protons and carbon ions. Three treatment rooms with four beam ports (three horizontal and one vertical), plus one room dedicated to experimental activities are presently available.

The CNAO synchrotron provides energies up to $400 \mathrm{MeV} / \mathrm{u}$ for carbon ions (corresponding to a maximum beam range of $27 \mathrm{~cm}$ in water) and up to $250 \mathrm{MeV}$ for protons (corresponding to $38 \mathrm{~cm}$ in water). In all the rooms, the beam is distributed with the same modulated scanning system, with an irradiation field size of $200 \times 200 \mathrm{~mm}^{2}$. The main specifications of the CNAO accelerator system are summarized in Table 1. The parameters have been defined by accelerator physicists, together with medical physicists and clinicians, with the aim to cover at best the requirements for an optimal hadron therapy treatment.

The original design of the accelerator complex comes from the Proton Ions Medical Machine Study (PIMMS [25,26]) held at CERN in the late nineties. The PIMMS design has been adapted by the TERA Foundation [27] to a more compact layout to favour its installation in a hospital environment (Figure 4 [28]). The facility in Pavia has been built between 2005 and 2009 with the collaboration of many institutions such as INFN, University of Pavia, University of Milan, Polytechnic of Milan, CERN, GSI (Society for Heavy Ion Research, Darmstadt, Germany), LPSC (Laboratory of Subatomic Physics \& Cosmology, Grenoble, France) and others.

Table 1. Main specification of the CNAO hadron therapy system.

\begin{tabular}{|c|c|}
\hline Beam particle species & $\mathrm{p}, \mathrm{He}^{2+}, \mathrm{Li}^{3+}, \mathrm{Be}^{4+}, \mathrm{B}^{5+}, \mathrm{C}^{6+}, \mathrm{O}^{8+}$ \\
\hline Beam particle switching time & $\leq 10 \min$ \\
\hline \multirow{3}{*}{ Beam range } & $1.0 \mathrm{~g} / \mathrm{cm}^{2}$ to $27 \mathrm{~g} / \mathrm{cm}^{2}$ in one treatment room \\
\hline & $3.1 \mathrm{~g} / \mathrm{cm}^{2}$ to $27 \mathrm{~g} / \mathrm{cm}^{2}$ in two treatment rooms \\
\hline & Up to $20 \mathrm{~g} / \mathrm{cm}^{2}$ for $\mathrm{O}^{8+}$ ions \\
\hline Bragg peak modulation steps & $0.1 \mathrm{~g} / \mathrm{cm}^{2}$ \\
\hline Range adjustment & $0.1 \mathrm{~g} / \mathrm{cm}^{2}$ \\
\hline Adjustment/modulation accuracy & $\leq \pm 0.025 \mathrm{~g} / \mathrm{cm}^{2}$ \\
\hline Average dose rate & $2 \mathrm{~Gy} / \mathrm{min}$ (for treatment volumes of $1000 \mathrm{~cm}^{3}$ ) \\
\hline Delivery dose precision & $\leq \pm 2.5 \%$ \\
\hline \multirow{2}{*}{ Beam axis height (above floor) } & $150 \mathrm{~cm}$ (head and neck beam line) \\
\hline & $120 \mathrm{~cm}$ (elsewhere) \\
\hline Beam size $^{1}$ & 4 to $10 \mathrm{~mm}$ FWHM for each direction independently \\
\hline Beam size step $^{1}$ & $1 \mathrm{~mm}$ \\
\hline Beam size accuracy $^{1}$ & $\leq \pm 0.25 \mathrm{~mm}$ \\
\hline Beam position step $^{1}$ & $0.8 \mathrm{~mm}$ \\
\hline Beam position accuracy ${ }^{1}$ & $\leq \pm 0.2 \mathrm{~mm}$ \\
\hline \multirow{2}{*}{ Field size ${ }^{1}$} & $5 \mathrm{~mm}$ to $34 \mathrm{~mm}$ (diameter for ocular treatments) \\
\hline & $2 \times 2 \mathrm{~cm}^{2}$ to $20 \times 20 \mathrm{~cm}^{2}$ (for $\mathrm{H}$ and $\mathrm{V}$ fixed beams) \\
\hline Field position accuracy ${ }^{1}$ & $\leq \pm 0.5 \mathrm{~mm}$ \\
\hline Field dimensions accuracy ${ }^{1}$ & $1 \mathrm{~mm}$ \\
\hline Field size accuracy ${ }^{1}$ & $\leq \pm 0.5 \mathrm{~mm}$ \\
\hline
\end{tabular}

${ }^{1}$ At isocentre. 


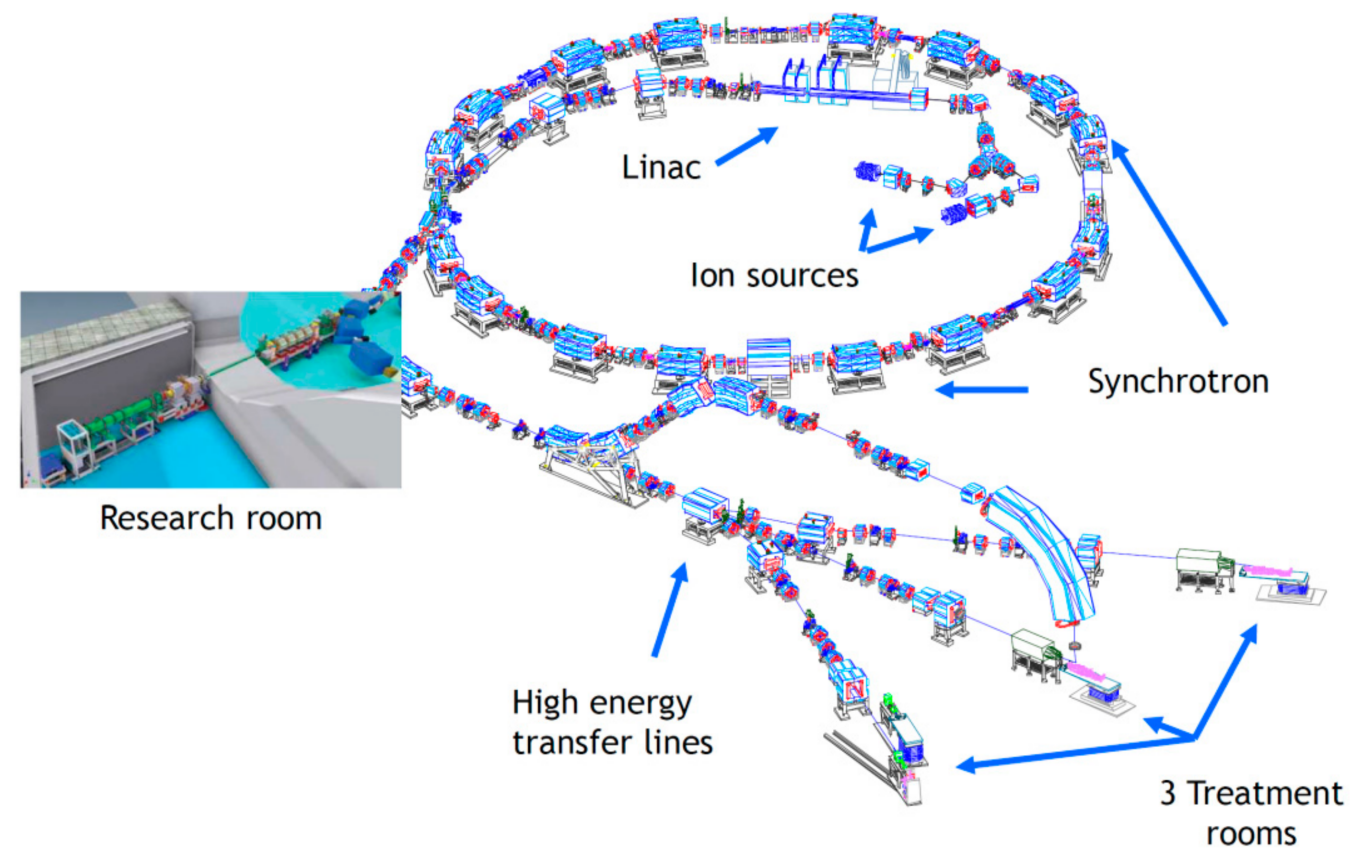

Figure 4. Model of the compact layout of the CNAO synchrotron: the injection chain is inside the ring and three horizontal beamlines are selected by a single fan-out magnet. Additionally, shown the experimental room. The diameter of the synchrotron is about $25 \mathrm{~m}$.

Research experiments are carried out at CNAO in the experimental room-built in collaboration with INFN-where the beamline can be arranged in different configurations according to either the space needed downstream the target or in terms of irradiation fieldsize dimensions. This room operates in parallel with the treatment rooms and is accessible independently from the patients' course, thus the setting up of the experiments does not interfere with the daily clinical activity. Laboratories with various technical equipment and additional preparation areas complete the research support services.

The treatment rooms are equipped with robotic devices that allow highly accurate automated patient positioning and reliable patient set-up verification through in-room imaging (Figure 5).

To cope with the intrinsic geometrical selectivity of particle therapy, the accuracy in patient positioning is $\pm 0.3 \mathrm{~mm}$ in translation and $\pm 0.1^{\circ}$ in rotation. At CNAO, the development of customized imaging devices has been the focus of a long-lasting collaboration with the Polytechnic of Milan. In particular, high payload robotic devices have been exploited to develop in-room volumetric imaging techniques based on rotating $C$-shaped arms (C-arms) equipped with X-ray tubes and digital detectors, capable of Cone Beam Computed Tomography (CT) imaging reconstruction and 3D (3-dimension)-3D registration [29]. Special tools have also been developed for the optical tracking monitoring of the online target displacement through infrared cameras mounted on the beam nozzle [30]. Similarly, a novel eye tracking system supported by a robotic arm is in clinical use for orienting patient's gaze direction and monitor eye position in the treatment of ocular lesions [31].

These technologies are in continuous evolution, СBCT being the state of the art and MRI on the roadmap, as it provides unique anatomical imaging and tracking for tumour and surrounding tissues, without giving unnecessary extradoses to the patient [32]. Seated positioning devices with vertical CT imaging are increasing in interest since they allow more flexibility and reduce the limitations, in the treatment geometry, imposed by the lack of a gantry (this subject is studied in Working Package 9 of HITRIplus; see also [33]). 


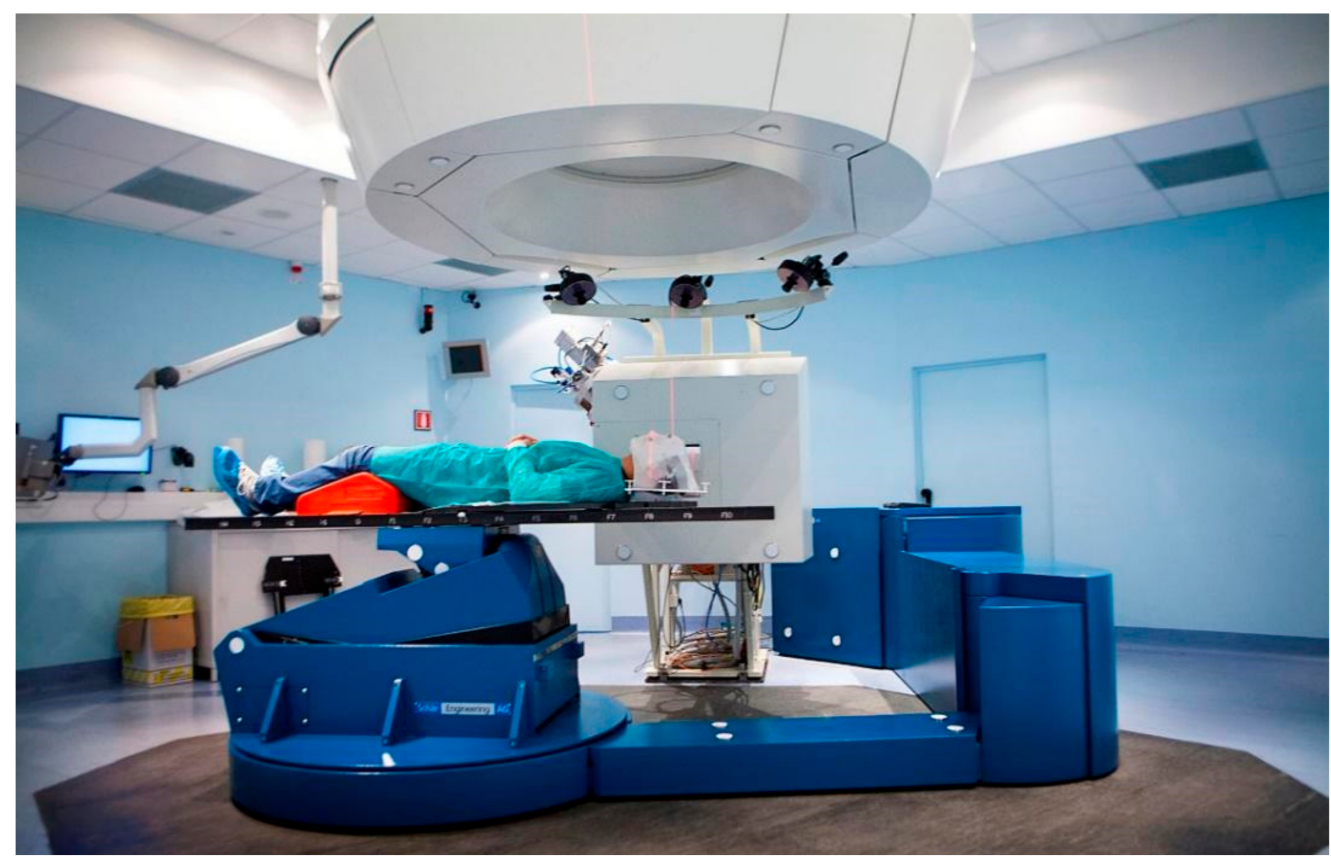

Figure 5. The alignment devices inside the CNAO treatment room. In blue the pantograph robotic couch with 6 degrees of freedom. On the ceiling, the cylinder that incorporates the two orthogonal $X$-rays tubes and the opposing flat panels. Above the nozzle are also visible three infrared cameras used to monitor on-line the spatial position of refracting markers placed on the patient's mask.

\subsection{Treatment Procedures at $C N A O$}

Each patient is immobilized with a custom thermoplastic mask. Multiple imaging systems (CT, magnetic resonance imaging (MRI) and CT-positrom emission tomography (PET)) are performed for precise identification of the target and organs at risk. During the planning stage, the dose delivery techniques are adapted to the patient anatomy, tailoring the number and the orientation of the beams. Safe dose limits for healthy organs have been the subject of extensive review work, carried out by incorporating known data for photon radiotherapy and, when available, particle therapy specific data. Prescription doses and fractionation scheme are based on Japanese experiences translated by Molinelli et al. and Fossati et al. [34,35].

The set-up validation takes advantage of image-guided radiotherapy procedures (IGRT) with a daily validation through stereoscopic radiographs and correction of translational and rotational errors by means of a 6 degrees of freedom robotic couch.

The complexity of the scenario is further increased by the routine treatment of lesions affected by the respiratory movement. This requires a flow of operations in order to ensure an accurate dose delivery to the patient. In this case, the procedures include specific aspects aimed at mitigating and compensating the distortion effect of the planned dose distribution, due to both the patient's breathing and the dynamic delivery of the dose (the so-called interplay effect). These procedures are known as 4-D planning and delivery. Patients undergo a preliminary CT and MRI, the former carried out in a respiratory gating regime and retrospective reconstruction techniques in selected breathing phases. The treatment plan is optimized at the end exhale phase and delivered in the same breathing condition. Beam extraction is synchronized with the patient's breathing, combined with a slice-by-slice dose repainting technique [36-38].

\subsection{CNAO Medical Device Operation and Performance}

At $\mathrm{CNAO}$, the daytime, from Monday to Friday, is mainly dedicated to patients treatments, from approximately 8 a.m. to 9 p.m. This schedule entails a double work shift, for a total of $13 \mathrm{~h}$ of clinical activity per day. During the rest of the day, hence mainly at night and during the weekends, the following activities are carried out: research; individual 
treatment plan measurements; quality assessment, modifications and improvement of the facility and its systems; ordinary and extraordinary maintenance; inspection; and preparation of the machine for clinical treatments. These activities are carried out following a precise schedule established to achieve efficient management and organization.

The main CNAO performances are listed in Table 2. The overall documented period of treatment time is ten years. The machinery availability in this timeframe has been $90.6 \%$, whereas the machinery utilization rate, for treatment purposes only, has been $68 \%$. Over a functioning time of 3401 days, the system had a total downtime of 284 days (including ordinary and extraordinary stops), with a "breakdown" to "functioning days" ratio of $1.1 \%$. This demonstrates the robustness of the project, indicates that the materials and systems involved are of high quality and underlines the maintenance effectiveness and the efficiency of the personnel responsible for extraordinary interventions.

Table 2. CNAO performances from first patient treatment (fall 2011) to end of 2021. The data of year 2021 are available until October; the last months are estimated assuming the same trend.

\begin{tabular}{cc}
\hline Years from 2011 to 2021 & Years 2021 (Estimate) \\
\hline 3401 running days & $329 \mathrm{dd}$ \\
2495 treatment days & $242 \mathrm{dd}$ \\
247 dd ordinary maintenance & $29 \mathrm{dd}$ \\
37 dd system breakdown & $0 \mathrm{dd}$ \\
System availability: $90.6 \%$ & $90.1 \%$ \\
System reliability (dd): $98.5 \%$ & $100 \%$ \\
System reliability (sessions) & $99.4 \%$ \\
\hline
\end{tabular}

A relevant performance parameter is the system reliability, computed as the ratio between unforeseen days off and planned days. The total reliability rate is $98.5 \%$, and in 2021 it reached 100\%. However, the most significant data are related to the number of hadron therapy sessions postponed due to delays cumulated during a standard working day. In 2021 the reliability rate in terms of treatment sessions was $98.4 \%$, corresponding to 161 sessions out of 10,034. A more detailed analysis shows that 32 sessions were rescheduled due to technical issues, while the remaining 129 sessions were due to clinical problems and/or patients' personal issues. The actual system reliability was therefore $98.4 \%$, consistent with the typical performance of high-quality industrial plants.

Another important indicator of the system productivity is the mean daily number of irradiation sessions: during the year, it was equal to 40, with a maximum of 55 sessions per day. This difference suggests that in principle the system can sustain a significant increase in the number of patients that can be treated. Lastly, the mean daily clinical treatment duration this year has been $12 \mathrm{~h}$ and $14 \mathrm{~min}$ that corresponds to a $94 \%$ occupancy, computed with respect to the total available clinical time. This can be attributed to the complexity of our clinical cases, which has consequences in the time spent in patient positioning and treatment preparation and results in lengthy occupancy of the treatment rooms.

\subsection{A New Ion Source at CNAO}

CNAO uses two identical commercial sources of the family ECR (Electron Cyclotron Resonance) Supernanogan [39] modified by CNAO with the INFN South Laboratories (INFN-LNS), of which one produces proton beams, the other carbon ions. These commercial sources have sufficient current intensities to minimize patients' treatment time and are characterized by high reliability, stability and reproducibility of the produced beams. The expansion plan, recently approved by the Ministry of Health, includes the addition of a third source, able to produce other ion species. The project has been financed by the Lombardy Region with European funds (project INSpIRIT-INnovative accelerator facility with Sources Ions for Research and radiation hardness studies with IndusTrial and clinical applications, [40]). 
The new ion species include helium ions, lithium, boron, oxygen, neon, argon and also iron, that are useful for bio-spatial research. The new source, called AISHa (Advanced Ion Source for Hadron therapy), has been realized by INFN-LNS and is based on the most recent theoretical developments in the field [41]. The project includes technological innovations that, compared to currently available sources, allow the achievement of higher performances in terms of charge state, current intensity and versatility of the ion species, while maintaining all features required for hospital settings. In Table 3, a list of ion species and related currents produced by AISHa are reported in comparison to the commercial ECR sources presently in use.

Table 3. List of ion species and related currents produced by ECR (Electron Cyclotron Resonance) sources presently in use at CNAO and by the new source AISHa (Advanced Ion Source for Hadron therapy).

\begin{tabular}{ccc}
\hline Ion & $\begin{array}{c}\text { ECR Sources } \\
(\mathbf{e} \mu \mathbf{A})\end{array}$ & $\begin{array}{c}\text { AISHa } \\
(\mathbf{e \mu A})\end{array}$ \\
\hline $\mathrm{H}^{+}$ & 2000 & 4000 \\
$\mathrm{H}_{2}^{+}$ & 1200 & 2000 \\
$\mathrm{H}_{3}^{+}$ & 1000 & 1500 \\
${ }^{3} \mathrm{He}^{+}$ & 800 & 2000 \\
${ }^{12} \mathrm{C}^{4+}$ & 250 & 800 \\
${ }^{6} \mathrm{Li}^{2+}{ }^{7} \mathrm{Li}^{2+}$ & -- & 800 \\
${ }^{10} \mathrm{~B}^{3+}{ }^{11} \mathrm{~B}^{3+}$ & -- & 600 \\
${ }^{16} \mathrm{O}^{6+}$ & 400 & 1200 \\
${ }^{21} \mathrm{Ne}^{7+}$ & 120 & 500 \\
${ }^{40} \mathrm{Ar}^{12+}$ & 20 & 140 \\
\hline
\end{tabular}

The third source will be installed inside the synchrotron ring in a configuration that allows the three sources to work simultaneously and will be initially used in the experimental room for research activities. Each source will maintain its functionality even if not in use for the subsequent acceleration stages. INSpIRIT also includes the low energy beam transport (LEBT) to inject the beam into the linac and new components for fast switching between ion species in the treatment rooms.

\subsection{In Vivo Range Verification}

The ability to monitor the beam path, and the energy absorbed by the traversed tissues, is one of the crucial aspects in the evaluation of the appropriateness of a treatment. The INSIDE project-Innovative Solutions for DosimEtry in hadron therapy [42]—was born with the aim of implementing a system for on-line monitoring the particle path in the patient, exploiting the detection of secondary radiations produced by the interaction of the beam with the nuclei of the tissues. The project is the result of a collaboration between CNAO, the Universities of Pisa and Turin, "Sapienza" Rome University, Centro Fermi of Rome, Bari Polytechnic and INFN.

INSIDE consists of an innovative bi-modal system, able to acquire data during patient irradiation. It is composed by an in-beam PET scanner and a charged particle tracker (called Dose Profiler). The PET scanner is realised with two flat panels, having an active area of about $10 \times 25 \mathrm{~cm}^{2}$ placed at $30 \mathrm{~cm}$ from the isocentre. PET detectors are based on fast scintillator pixels, coupled one-to-one to silicon photomultipliers. The information provided by the PET system can be improved with the knowledge of the beam profile inside the patient, measured by tracking the secondary particles (mainly protons) emitted by fragmentation in the interactions with the nuclei of the crossed tissues. The Dose Profiler [43] consists of eight planes of scintillating fibres, which provide the coordinates of the emission point of the secondary proton.

The two detectors are integrated in a mobile structure. Its geometry has been optimised to fit the CNAO treatment room as shown in Figure 6. 


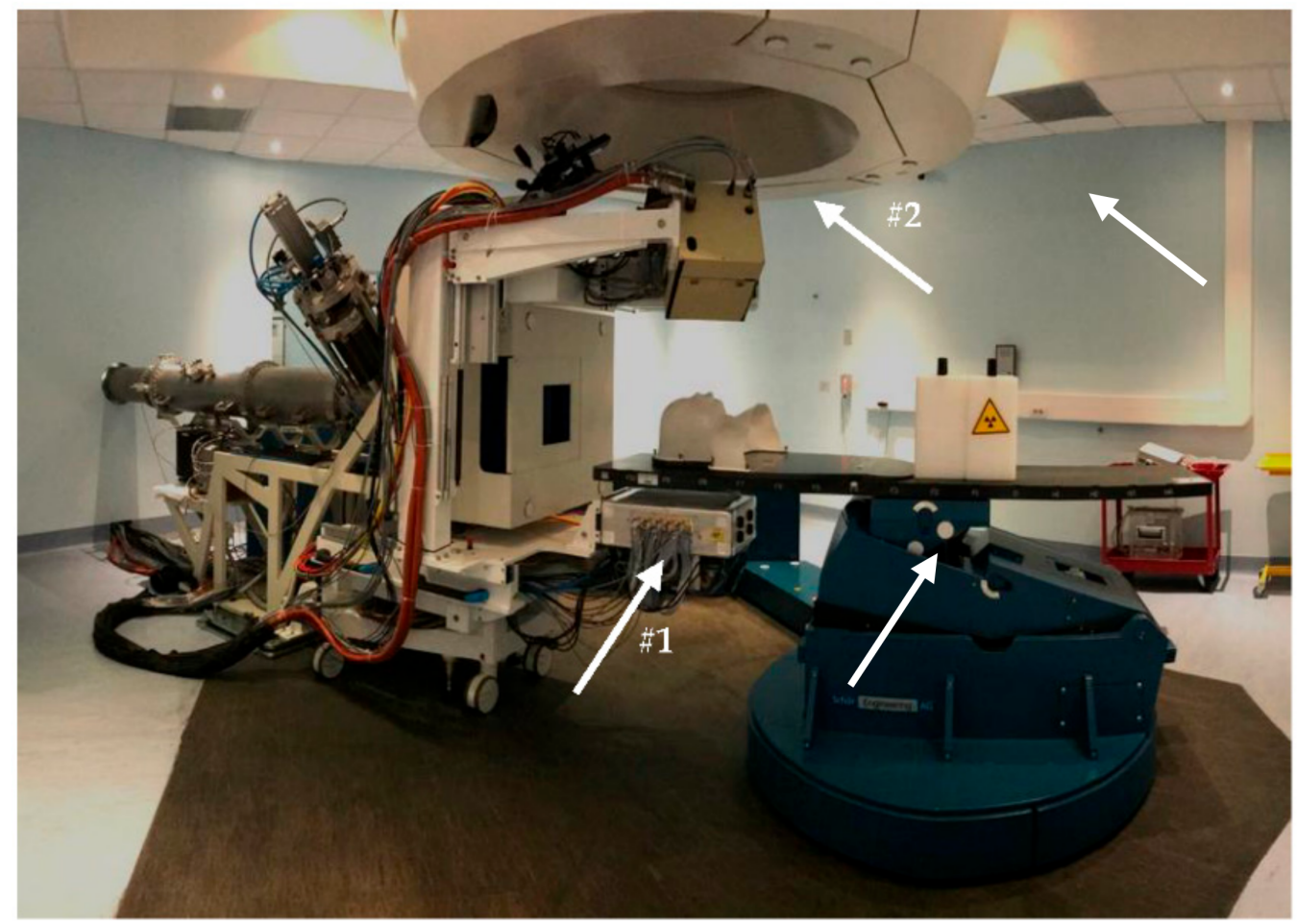

Figure 6. The INSIDE (INnovative SolutIon for DosimEtry in hadrontherapy) system in the treatment room: the lower in-beam PET (position emission therapy) detector is placed just under the couch (indicated by arrow \#1) and the dose profiler is in the foreground above the patient mask (indicated by arrow \#2).

An integral part of the project is the tuning of a range control procedure based on the comparison of the predicted signal with the signal measured by the two systems. This objective is pursued through the development of Monte Carlo simulations, using algorithms for image reconstruction and automatic analysis of PET images and charged particle emission maps.

In December 2016, the first in vivo test with the in-beam PET detector showed the capability of the system to acquire data during patient irradiation, reconstruct a dynamic image and evaluate the particle range agreement within $2 \mathrm{~mm}$, both by comparing two consecutive days irradiations and experimental data with a Monte Carlo simulation [44,45]. In July 2019, a clinical trial with the bi-modal INSIDE system [46] started at CNAO, recruiting 40 patients affected by specific head-and-neck and brain pathologies, treated with protons or carbon ions. The goals were to assess the performance of the system in a clinical situation while estimating the impact on the workflow, to verify the possibility to detect inter-fractional morphological changes in patients (due to tumour shrinking, inflammation effects) and to propose an effective way to present the treatment verification results to the physician. By February 2020, the first part of the clinical trial was completed by treating 20 patients. The use of the INSIDE bi-modal system did not slow down the CNAO clinical workflow. The results obtained with the in-beam PET scanner on proton patients were summarized in Ref. [47], showing the capability of detecting inter-fractional morphological changes. This information was used to define a Compliance Map that is a useful graphical representation to allow the detection of range differences. Ref. [48] describes another approach of PET images analysis tested with a Monte Carlo study. It relies on the detection of the regions that have a significant intensity change in the PET images by means of Voxel Based Morphometry technique. The volume of these PET regions showed a linear correlation with the volume of the morphological modification in the patient CT.

Ref. [49] summarizes the results of inter-fractional morphological change identification on carbon ion patients, using the Dose Profiler. By matching the secondary particle tracks 
with the axis of the primary incoming beam, Point of Closest Approach (PCA) 3D maps have been reconstructed and compared both with other experimental PCA of the same patient and with Monte Carlo simulations. In the case of patients in which morphological changes occurred, the Dose Profiler was able to detect the discrepancy using the $\chi^{2}$ test. Moreover, the clinical data acquired allowed to study the capability of the Dose Profiler to monitor in vivo the actual transverse position of the beam [50].

\subsection{Improving Delivery Technology}

In order to perform the treatment correctly and quickly, high-performance instruments that measure the characteristics of the particle beams and guide the systems that deliver the dose to the tumour are needed. The CNAO Foundation is developing, in collaboration with GSI and INFN, a new generation of active beam delivery monitoring system, the so-called Dose Delivery System 4.0 (DDS4) [51].

The project is structured with the goal to develop an online adaptive capability of the treatment, for motion compensation, managing intra-fraction target changes and accounting for inter-fraction changes. All these tasks are based on images, measurements and online software rework of the treatment plan. The DDS4 is an evolution of the present DDS clinically in use at CNAO and MedAustron and aims to deal with state-of-the-art accelerator technologies, such as: dynamic intensity control: fast variation of the beam intensity during scanning of one tumour slice; extraction pause for beam gating; multi energy extraction during one synchrotron cycle. One major specification of the DDS4 electronics is the processing time of one beam spot, performed ten times faster than the existing DDS.

A topic of recent discussion in radiotherapy is the possible reduction of side effects by providing extreme dose rates $>50 \mathrm{~Gy} / \mathrm{s}$, the so-called FLASH therapy [52]. It is unlikely that FLASH doses $>50 \mathrm{~Gy} / \mathrm{s}$ are feasible with current particle scanning systems, under clinical conditions and for large volumes. The delivery speed should be increased by several orders of magnitude. The electronics of DDS4, its rapid monitoring capabilities and the use of sophisticated range modulators are suited to introduce delivery strategies in view of FLASH. This will allow studies on animal models, providing answers about the impact of FLASH therapy both on side effects and on tumour control.

\subsection{Improving the System Efficiency}

State-of-the-art ion therapy centres rely on the three-dimensional intensity-controlled raster scanning technique to deliver the dose to patients [53]. Optimised linac-synchrotron combinations generate variable energy, focussed beams with adjustable intensity for the scanning and continuous dose measurement during a treatment [54]. In total, more than 100,000 beam parameters combinations must be provided per treatment room. This method allows high-precision delivery of inversely planned and biologically optimised dose distributions. The target volume is dissected into a series of iso-energetic slices, each irradiated by a slowly extracted beam having a constant energy selected during the treatment planning process from a list of predefined beam characteristics. Thus far, each synchrotron cycle provides only one energy, even though the intensity of the circulating beam would allow more slices to be scanned.

Multi-energy operation is a possible future mode of synchrotron operation using the technique known as RF knock-out [55]. Instead of discharging the remaining particles at the end of the extraction phase, they will be accelerated or decelerated to a close-by energy level. In a typical treatment scheme, the iso-energetic slices have a distance of only a few millimetres, corresponding to an energy difference of $\leq 4 \mathrm{MeV} / \mathrm{u}$. In such an irradiation scheme, several slices can be irradiated with short interruptions. Phases without beam availability in the treatment room will be drastically reduced by saving up to $50 \%$ of the irradiation time. This approach will be studied by HITRIplus Working Group 10. 


\subsection{Single Room for Proton Therapy}

The initial decision of CNAO to focus, above all, on the use of carbon ions, led to the adoption of fixed, horizontal and vertical beams. Carbon ions indeed, in addition to great precision, can claim an increased radiobiological efficacy that allows a good distribution reached with the only use of fixed beams. However, the unavailability of a proton gantry represents a limitation, which CNAO initially decided to accept. The recent technological progress has made available interesting, compact and affordable solutions to have available rotating beams of protons. The gantry allows the beam to move around the patient, reducing patient positioning times on one hand, and increasing therapeutic solutions on the other.

The installation of a proton accelerator serving the new gantry has a dual purpose: it ensures independent productivity in terms of patient throughput and it is a back-up solution for patient treatments in case of maintenance or downtime of the existing synchrotron. On 5 December 2019, CNAO Foundation signed a contract with Hitachi Ltd. for the supply of a new synchrotron and a proton gantry. Figure 7 shows the model of the Hitachi's single room system and Table 4 summarizes the main characteristics of the new facility.

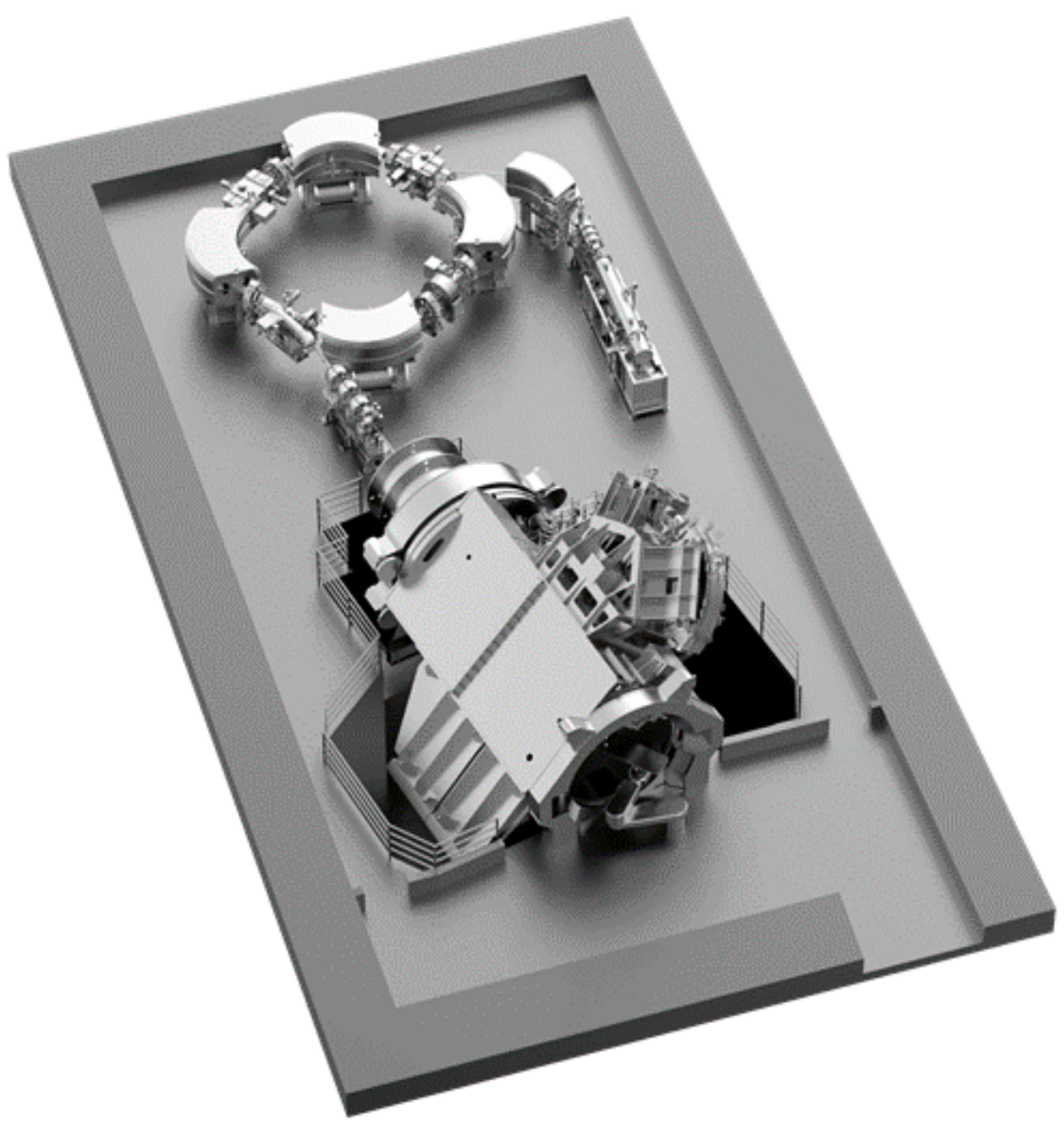

Figure 7. Model of the proton therapy technology proposed by Hitachi (courtesy of Hitachi).

The maximum treatment field, equal to $30 \times 40 \mathrm{~cm}^{2}$, has been one important parameter in the evaluation of the system performances. This is particularly useful to treat extended pelvic lesions and paediatric patients, when cranium-spinal irradiations are necessary: a 
large treatment field avoids the necessity of treatment techniques that employ multiple isocentres and consequent junction of adjacent fields and reduces the overall criticality of the treatment plan.

It has to be stressed that the Hitachi's proton synchrotron is similar to the existing synchrotron at CNAO, thus allowing the involvement of CNAO personnel in the management phase, saving on maintenance costs and enhancing the rapidity of any intervention. Other synergies will certainly occur in the development of innovations applicable to both systems.

Table 4. Main characteristics of the Hitachi system to be installed at CNAO.

\begin{tabular}{|c|c|}
\hline Item & Specification \\
\hline Accelerator & Synchrotron \\
\hline Species & Proton \\
\hline Energy & $70-230 \mathrm{MeV}$ \\
\hline Maximum range & $32 \mathrm{~g} / \mathrm{cm}^{2}$ \\
\hline Minimum range & $4 \mathrm{~g} / \mathrm{cm}^{2}$ \\
\hline Maximum field size at isocentre & $40 \mathrm{~cm} \times 30 \mathrm{~cm}$ \\
\hline Dose rate & $\geq 1.4 \mathrm{~Gy} / \mathrm{min}$ \\
\hline Range modulation method & $\begin{array}{c}\text { Energy stacking by energy change with accelerator or } \\
\text { change of range shifter thickness }\end{array}$ \\
\hline Gantry & 360 degrees rotating gantry \\
\hline Robotic couch & 6 DOF swing robotic couch with error correction \\
\hline Imaging & $\begin{array}{l}\text { Orthogonal imaging device (radiography, fluoroscopy, } \\
\text { CBCT with real time imaging capability) }\end{array}$ \\
\hline
\end{tabular}

\subsection{BNCT, a Hope for the Cure of Metastatic Cancers}

Boron Neutron Capture Therapy (BNCT) is an experimental form of hadron therapy, based on cancer irradiation with neutrons following perfusion with a boron compound able to concentrate ${ }^{10} \mathrm{~B}$ atoms in cancer cells. The thermal-neutron capture reaction on ${ }^{10} \mathrm{~B}$ is highly probable and generates two ionizing particles: an $\alpha$ particle and a ${ }^{7} \mathrm{Li}$ ion. These particles lose all their energy over a distance that is comparable with the cell diameter and can cause irreversible damage to DNA as they pass through the nucleus. If enough boron is captured by the tumour cells, so that a high concentration ratio of boron is obtained between the tumour and the healthy cells, a neutron irradiation may deliver a therapeutic dose to the tumour, sparing the healthy tissues. The selectivity of this therapy is based on the bio-distribution of boron, rather than on the irradiation field. This makes the BNCT a suitable option for the treatment of diffuse tumours: the neutron irradiation of the entire organ would affect all tumour nodules without the need to know their number, distribution or shape [56].

The development of accelerator-based neutron sources, replacing nuclear reactors, represents the most important recent innovation in the field of BNCT [57]; for this reason, this technique and its application to new tumours is being deployed in hospital environment. Figure 8 shows the Tandem accelerator produced by the US company TAE Life Sciences (TLS). A collaboration agreement between TLS and CNAO was signed on 22 November 2020, and it will provide the accelerator, beamlines, beam shaping assembly (BSA) and patient positioning for the BNCT at CNAO. For the first time in Italy, a relatively small particle accelerator for the production of neutron beams will be installed in a dedicated space, intended for clinical and research activities. This machine will be made available to a consortium (formed by CNAO with INFN, University of Pave, Polytechnic of Milan and open to international collaborations) to launch the pre-clinical and clinical trials intended to demonstrate the safety and efficacy of BNCT. 


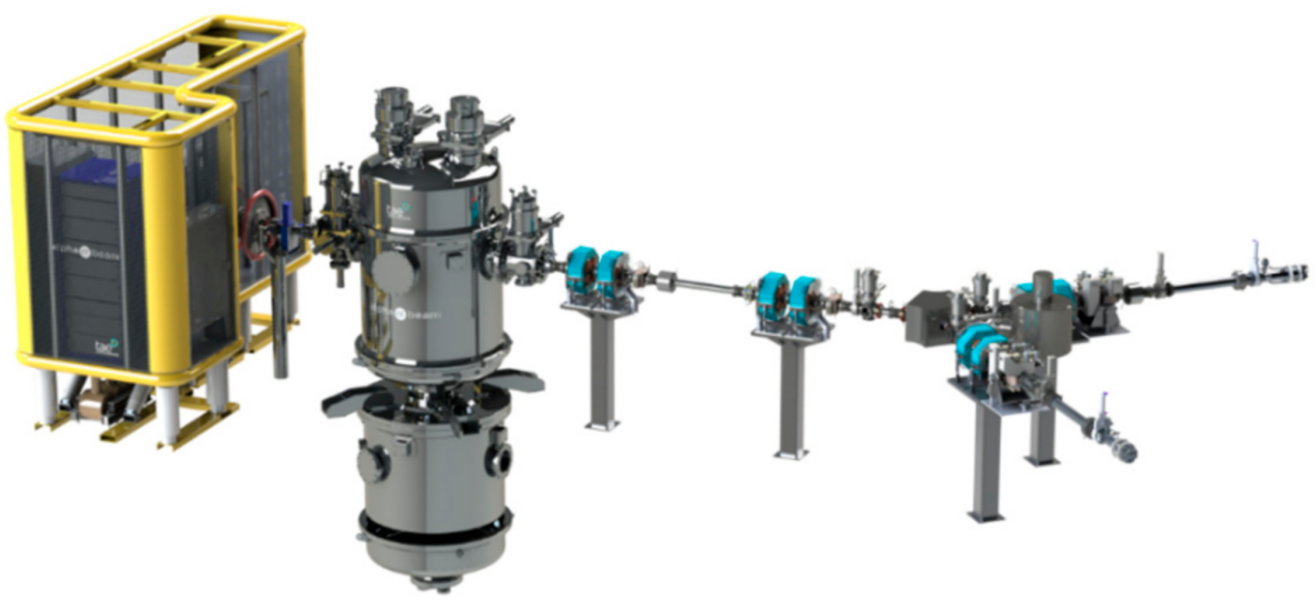

Figure 8. Tandem accelerator with source (on the left) and beamlines. The proton beam energy is $2.5 \mathrm{MeV}$ and the intensity is $10 \mathrm{~mA}$ (courtesy of TLS-TAE Life Sciences).

\section{Theoretical Part}

\subsection{Modelling and Methodologies for a Patient Specific Therapy}

CNAO, in collaboration with Polytechnic of Milan, is performing research studies related to the integration of patient-specific multi-parametric imaging with advanced mathematical models that detect macroscopic, microscopic and radiobiological information. The goal of these studies is to enhance the treatment response prediction, the patient stratification and the subsequent optimization and personalization of hadron therapy. Figure 9 summarizes the various activities that are underway within the framework of the CNAO-Polytechnic of Milan collaboration.

These studies involve the collection of imaging data such as CT, dose mapping, anatomic and quantitative MRI (for instance, diffusion (DWI) and perfusion-weighted (PWI) MRI). These data are then integrated with mathematical models, such as radiomics, artificial intelligence (machine learning) and microstructural models, in order to derive, at different scales, indices that allow for the optimization of treatment strategies on an individual patient basis. These models will serve both as radiotherapy decision-making tools towards an optimized and personalized medical approach and as a support tool to quantitative clinical decisions.

To date, on a macroscopic scale, one of the main research activities concerns the use of radiomics and dosiomics, in patients with basal-cranial chordomas treated with CIRT [58]. In particular, CT images, dose mapping and anatomical MRI for 57 patients were used to derive features capable of predicting local control, with promising results regarding attributes extracted from dose maps.

Another research activity aims to investigate the potential of quantitative MRI, such as DWI and PWI. DWI images were in fact employed to derive information related to tumour cellularity in 20 patients affected by skull-base chordoma and treated with CIRT. The patient-specific cellularity data then served to feed a customized local control probability model, which showed more conservative local control predictions with respect to conventional prediction models [59]. In addition, in patients enrolled in proton therapy, DWI and PWI image analyses were performed for grading meningioma. Twenty-six patients were retrospectively selected. For these patients, since lesion histology and other clinical information were available, both PWI (Dynamic Contrast Susceptibility, DSC) and DWI (Intra Voxel Incoherent Motion, IVIM) sequences were acquired prior to treatment. From the multi-parametric MRI analysis, IVIM parameters were found to be promising biomarkers for the characterization of low and high-grade meningiomas [60]. 


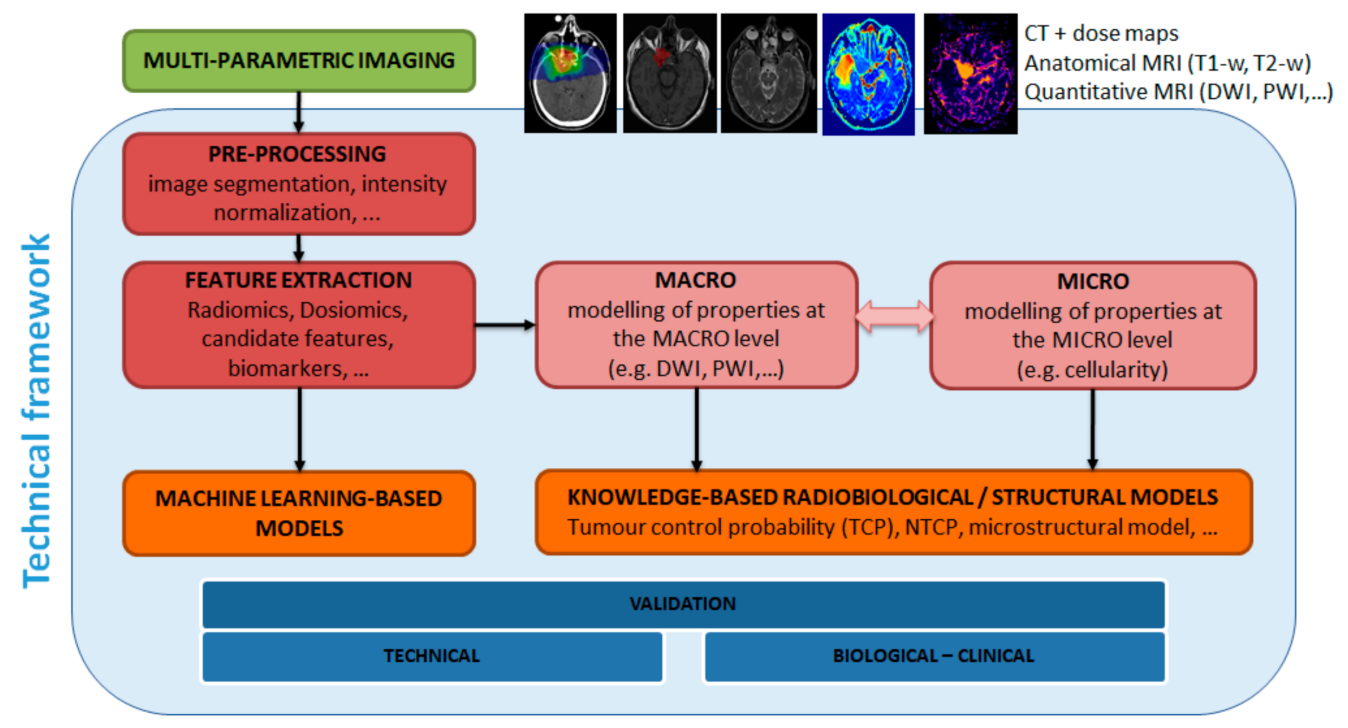

Figure 9. Studies ongoing at CNAO to integrate methodologies oriented towards a patient-specific therapy.

In addition, the evaluation of radiation-induced toxicities, to reduce the effects of radiation on healthy tissues surrounding the lesion, is underway. In particular, a study on the spatial normalization of dose distributions for toxicity analysis was led by VBA (Voxel-Based Analysis). This method has been applied to 50 patients with meningioma treated with proton therapy. The study, carried out in collaboration with the Institute of Biostructures and Bioimaging (IBB) of CNR (Consiglio Nazionale della Ricerca), Naples section, led to the definition of a better procedure for the spatial normalization of the dose, which lays the foundations for future toxicity studies [61]. With regard to this toxicity analysis, a study evaluated the diffusion and perfusion variations in the white matter of patients suffering from meningioma and treated with proton therapy. Preliminary analyses have shown that dose and time are variables able to influence the diffusion and perfusion parameters of white matter [62].

Lastly, as part of a collaboration with the Center of Medical Image Computing (CMIC) of the University College London (UCL), a microstructure model has been applied starting from diffusion-weighted imaging techniques. The model is capable of deriving quantitative indices on a microscopic scale (for instance, radius of the cells), both for non-invasive histological characterization of meningiomas and for the evaluation of structural changes induced by proton therapy [63].

\subsection{Treatment Planning, Monte Carlo and Adaptive Protocols at CNAO}

The TPS currently in use at CNAO is Raystation v.8B [64], which will be soon updated to v.10B. All versions of the TPS are commissioned against experimental measurements and an independent Monte Carlo system (Fluka) to ascertain dosimetric accuracy in homogeneous and inhomogeneous conditions before clinical implementation [65]. The new version of the TPS will allow fast Monte Carlo calculation of proton treatment plans and multi-model RBE-weighted dose optimization and evaluation of carbon ion plans. RBE modelling has been shown to significantly affect treatment outcomes in CIRT for the treatment of adenoid cystic carcinomas (ACC), skull-base chordomas and sacrum chordomas, both in terms of prescribed dose and organs at risk constraints [66].

In collaboration with the Heidelberg ion therapy centre, an independent dose and LET calculation system (FRoG) has been developed to assess the impact of dose averaged LET distribution on treatment outcomes [67], a topic that has gained more and more relevance in the last years. The LET influence on treatment toxicity is currently under evaluation for brain necrosis in IMPT (Intensity Modulated Proton Therapy) for skull-base tumours and bone and sciatic nerve injuries in CIRT to pelvic tumours. 
Robust plan optimization is the optimal choice, unless computational limitations forbid it, accounting for set-up and range uncertainties. Patient set-up is verified and corrected, on a daily basis, by means of $\mathrm{kV}$ orthogonal images and 3D-CBCT. Daily CBCT were recently analysed, to assess the dosimetric impact of inter-fraction anatomical changes in CIRT boost for high-risk prostate cancer [68]. All patients follow an offline adaptive protocol and undergo a re-evaluation CT, with a frequency that depends on the tumour site and involved uncertainties. When the treatment site entails target motion and anatomy variability, mitigation strategies include patient immobilization with a solid thermoplastic mask, 4DCT acquisition and gated dose delivery, combined with rescanning. For this patient group, multiple pre-treatment 4DCTs are acquired, together with multiple breathing phases, both to verify respiratory pattern and patient anatomy reproducibility before treatment.

CNAO is concurrently studying the generation of virtual 4DCT images from 4DMRI to detect clinically relevant deviations in the pattern of motion, while minimizing additional dose to the patient [69]. A collaboration with Polytechnic of Milan, in the framework of the RAPTOR project [70], will be focused on this topic and on the use of CBCT for daily treatment adaptation.

Finally, the implementation of an NTCP (Normal Tissue Complication Probability) model-based selection approach for IMPT for nasopharyngeal cancer and mediastinal Hodgkin lymphoma is underway [71], to support clinical decisions in view of the nearfuture installation of a proton gantry.

\section{Results}

\subsection{Pre-Clinical Radiobiology Research}

In recent years, radiation biology is experiencing a shift in the research topics, from more classical cellular end points, such as DNA damage and RBE quantification, to studies of the tissues and of the microenvironment [72]. For example, it is well recognized that lowLET ionizing radiation might promote migration and invasion of tumour cells, while the few data collected so-far with high-LET radiation studies do not lead to clear conclusions [73]. What is known to be fundamental in the modulation of migration of tumour cells exposed to ionizing radiation is the influence of the microenvironment. Therefore, the study of the influence of radiation on the migratory and invasive capacity cannot ignore the cells that populate the tumour stroma, especially in the case of pancreatic cancers, that is characterized by abundant stroma cells including cancer-associated fibroblasts, which are known to orchestrate the crosstalk with tumour cells [74].

For this reason, thanks to a collaboration with Polyclinic San Matteo, CNAO is evaluating the cellular effects of carbon ion irradiated pancreatic adenocarcinoma cells and mucosal melanoma cells using extracellular matrix (ECM) scaffolds obtained through organ decellularization. Compared to 2D cell cultures, these ECM-derived bio-scaffolds retain growth factors, cytokines and chemokines that facilitate cell attachment, tissue integration, remodelling and differentiation. Furthermore, these scaffolds guarantee the transport of oxygen and nutrients to the seeded cells and ensure the physiological exit of the waste metabolites produced by the cells [75]. With this experimental approach, one can create in vitro a 3D growth microenvironment that mimics very closely the native tissue and it is, therefore, possible to evaluate more comprehensively the biological effects of radiations.

Together with direct invasion of surrounding tissues, perineural invasion is another crucial route of cancer spread, since numerous tumour cells have an innate ability to actively migrate along nerves, thanks to the signals of various molecules secreted by both tumour cells and non-tumour cells of the microenvironment [76]. Very few studies have addressed the influence of photon radiotherapy on this type of spreading, although it is considered as a marker of poor prognosis for numerous malignant neoplasms, including head-and-neck, pancreatic, prostate, colorectal, and salivary cancers. With the aim of providing useful information for the treatment with hadron therapy of these types of tumours, at CNAO a research group has started to investigate in vitro the influence of high LET radiation on migration and invasion of salivary gland adenoid cystic carcinoma and 
mucosal melanoma cells after different irradiation protocols, using also Neurotrophin-3 and specific inhibitors/antagonists.

To date, the reasons for the inter-individual variability of the response to radiotherapy within the same group of tumours with the same histology/site/stage are not known, nor is the origin of the different radiosensitivity of the irradiated healthy tissues. Thus, pre-clinical carbon ion radiobiology urgently needs also studies aiming at guiding patient selection and treatment protocols to achieve optimal clinical results. In this direction, $\mathrm{CNAO}$ researchers have recently started an experimental project to study the radio-sensitivity and induced molecular alterations of different radiation types on cancer-derived models and on organoids of head-and-neck squamous cell carcinomas [77]. Although local control is generally very high with carbon ion beams in most malignancies, in some cases radiotherapy must be combined with systemic therapies to control metastasis and increase survival. Nevertheless, to date very few radiobiology studies specifically investigated the potential synergistic interactions of chemotherapeutic agents/radio-sensitizer and ion irradiations. CNAO research is moving towards the evaluation of an inhibitor of apoptosis proteins as radio-sensitizer combined with protons or carbon ions, to provide the biological background supporting future clinical trials with particles radiotherapy combined with these drugs in head-and-neck cancer patients.

Finally, since the use of immunotherapy has become a critical treatment modality in many advanced cancers, one of the most asked questions in clinical radiobiology of carbon ions concerns the speculations that these irradiations may enhance tumour immunogenicity and, consequently, whether abscopal effects and the combination CIRT with immunotherapy can produce better clinical outcomes [78].

\subsection{Clinical Activities: Pathologies and Results}

CNAO treated more than 3700 patients with a wide range of pathologies, whose incidence rates are indicated in Figure 10. A little more than half of them (55\%) were treated with carbon ions.

After an initial clinical trial stage, it is necessary to obtain the CE certification for the CNAO medical device. The number of treated patients per year has grown year after year (Figure 10). Currently, the Centre treats almost 600 patients yearly and its operational capacity might be increased by about $20 \%$. The Italian Ministry of Health has introduced a list of pathologies for which treatments are authorized and reimbursed by the National Health System, the so-called Essential Levels of Assistance (LEA). The admitted pathologies are the following ten:

1. chordomas and chondrosarcomas (of the skull base and of the spine);

2. meningioma;

3. brain tumours (trunk);

4. adenoid cystic carcinomas of the salivary glands;

5. orbit tumours including eye melanoma;

6. sino-nasal carcinomas;

7. soft tissue and bone sarcomas (all sites);

8. recurrent tumours (retreatment);

9. patients with immunological disorders;

10. paediatric solid tumours.

The Health Ministry is currently discussing other categories considering selection criteria based on the evolution of NTCP or Tumour Control Probability (TCP). NTCP-based patient selection for haematological malignancies is currently being implemented at CNAO in collaboration with Institut Curie of Paris (France). Within the ten categories identified by the LEA, it is estimated that each year, in Italy, around 5000 patients should be treated with protons and around 1000 with carbon ions over a total population of 60 million.

For this reason, it appears essential to create a network, where CNAO operates as a hub, connected to other future national proton therapy centres. This distribution model is ideally interesting, but it needs solid and defined patient selection mechanisms and strong 
interdisciplinary interactions between $\mathrm{CNAO}$ and other hospitals, to manage the all-around complexity of particle therapy patients.

Patients' data show that almost $25-30 \%$ were treated at CNAO in a re-irradiation setting and $15 \%$ of patients have large tumour volumes $(>500 \mathrm{cc})$; nevertheless, the local control appears promising and consistent with the literature data available for similar hadron therapy treatments.

The loco regional toxicities, routinely scored with Common Toxicity Criteria Adverse Events (CTCAE), are mild and in some cases even better than literature, thanks also to the performance of the active scanning system and the careful treatment planning.

During the last two years more than 100 papers were published in scientific journals by CNAO researchers. In 2021, 50 publications with overall Impact Factor 290.5 were published. It is not the purpose of this text to present the clinical results related to the single pathologies, but a small summary of the most common diseases treated at CNAO is here outlined, presenting data on skull bases chordomas, head-and-neck tumours and malignant mucosal melanoma. Data are taken from a literature review of the Scientific Direction, in collaboration with the medical staff and with the Istituto Mario Negri (Milan, Italy).

\subsection{Skull Base Chordoma and Chondrosarcoma}

Chordoma is a rare primary bone tumour arising from notochord remnants with an incidence of $0.8-1$ per million, with approximately one-third arising from the midline clivus and skull-base. Chondrosarcomas are malignant cartilaginous tumours that occur in approximately 1.0 per 2 million at the skull base. For both these tumours, the importance of surgery has been well established. Complete resection is desired as optimal goal of surgical procedure; however, it is often precluded by tumour location and the surrounding critical structure such as brainstem or optic pathways.

As a result, any residual or microscopic disease is targeted by radiation therapies to reduce the risk of disease recurrence or progression and improve prognosis. To date, photon radiation is the most accessible radiation modality; however, the major limitation of this modality for skull base chordomas and chondrosarcomas is that the delivery of the required dose is limited by the risk of injury to adjacent normal structures, such as the brainstem and visual pathway. Particle beam therapy (proton therapy (PT) and CIRT) appears to be the most effective radiation modality in the management of skull-base chordomas, allowing the delivery of high radiation dose levels, maximizing the positive balance between Gross Tumour Volume (GTV) optimal dose coverage and organ at risk sparing. Moreover, CIRT has several theoretical advantages: (1) it has a sharper penumbra than PT, allowing even better normal tissue sparing; (2) it is less dependent on fractionation; and (3) it has a higher relative biologic effectiveness in comparison to other modalities with respect to tumour cell death.

For the case of chordoma, in Iannalfi et al. 2020 [79], a collection of 135 patients (70 PT and 65 CIRT) treated at CNAO between November 2011 and December 2018 has been analysed. PT was delivered with a total dose of 74 Gy in 37 fractions, while CIRT total dose was $70.4 \mathrm{~Gy}(\mathrm{RBE})$, delivered in 16 fractions. CIRT has been used in more complicated cases. After a median follow-up of 44 (range, 6-87) months, $14(21 \%)$ and $8(11 \%)$ local failures were observed in CIRT and PT group, respectively. Five-year local control (LC) rate was $71 \%$ in CIRT cohort and $84 \%$ in PT cohort. The estimated 5-year overall survival (OS) rate in the CIRT and PT group was $82 \%$ and $83 \%$, respectively. On multivariate analysis, optic pathways and/or brainstem compression and dose coverage are independent prognostic factors of local failure risk. High-rate toxicity grades $\geq 3$ were reported in $11 \%$ of patients. Generally, the main role of particle radiotherapy in the treatment of chordomas has obtained wide consensus. Prospective observational studies and/or registries can help to find prognostic factors for local control and survival and to provide criteria for a patient-customized treatment strategy. Model-based approach can be useful to define toxicity risks for critical issues as temporal lobe necrosis. 


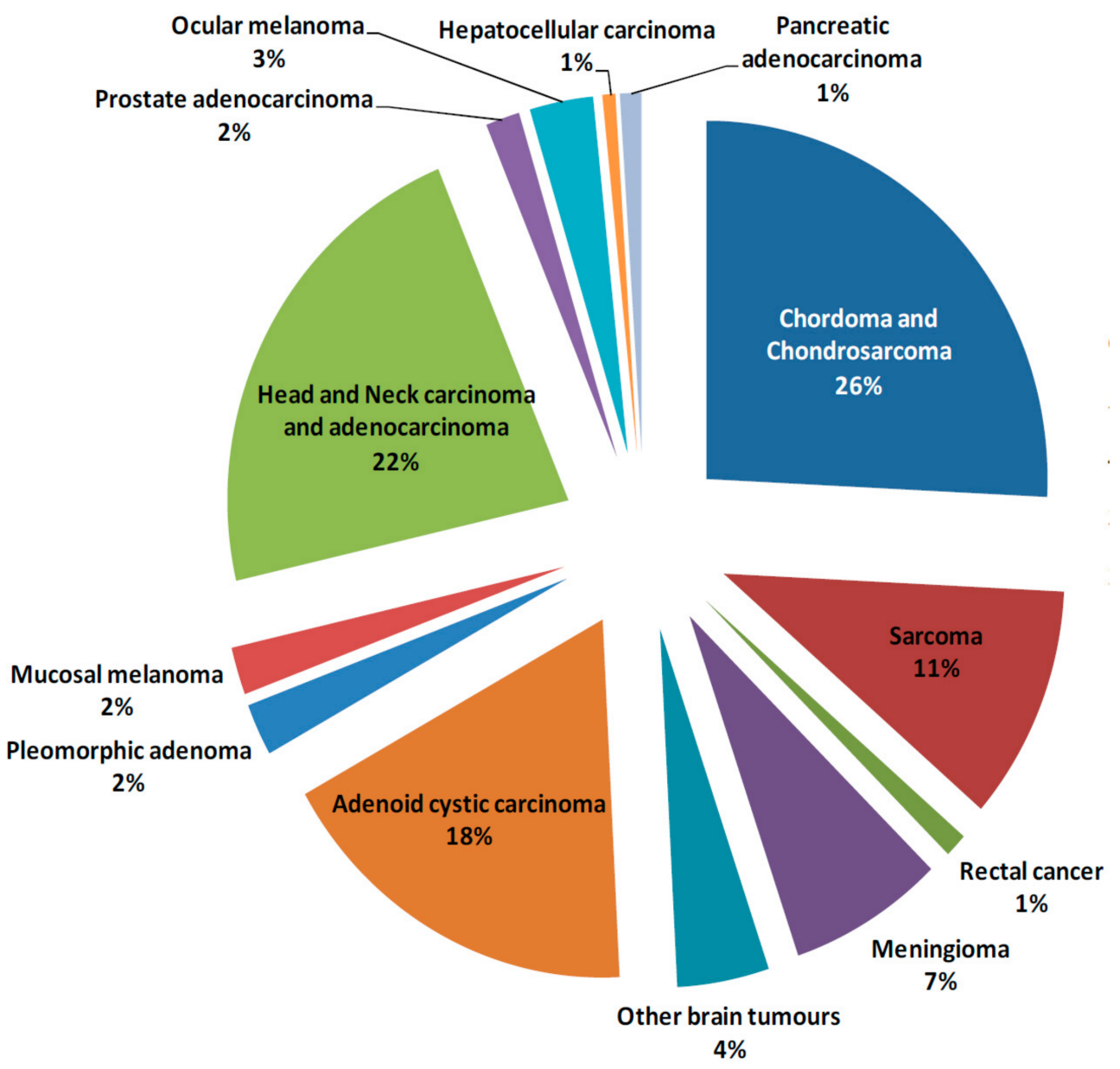

(a)

\section{CE clinical}

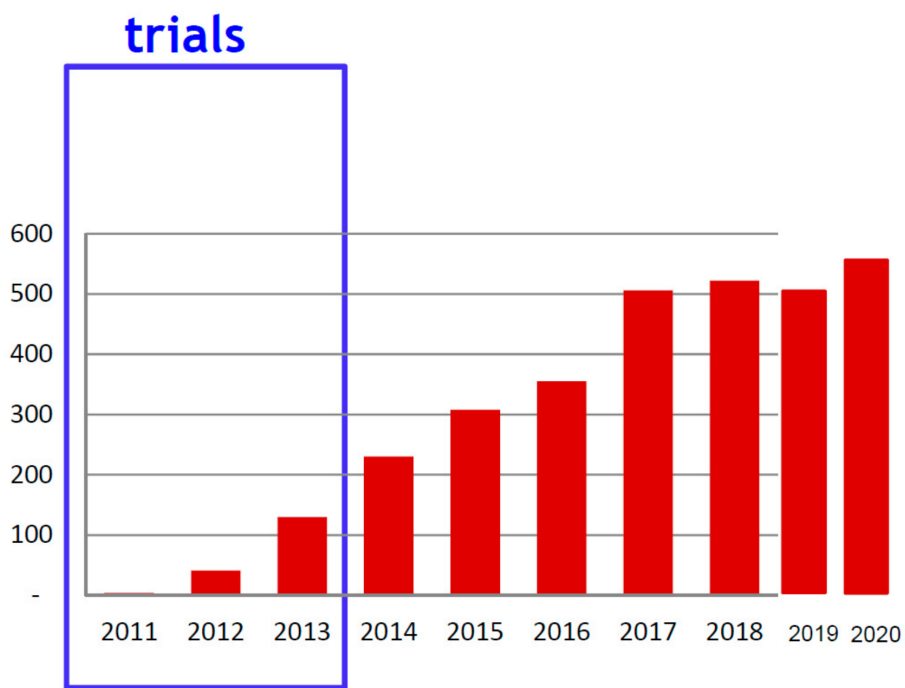

\section{Patients per year}

(b)

Figure 10. (a) Incidence of tumour pathologies treated at CNAO; (b) Number of patients treated each year at $\mathrm{CNAO}$. 


\subsection{Head-and-Neck Tumours}

Historically, radiation therapy has played an essential role in the management of head-and-neck cancers (HNCs), in various clinical settings. Modern technologies, including intensity modulated radiation therapy (IMRT) and volumetric modulated arc therapy (VMAT), have aided decreasing beam-on treatment time and making the delivery of photon radiation therapy more conformal and precise. Consequently, these technologies have reduced late toxicities, such as xerostomia, trismus, temporal lobe necrosis, neurological injury, and hearing impairment. In the landscape of treatment advancement for HNCs, particle therapy plays an important role. Recently, IMPT, thanks to its physical and biological features, has emerged as a potentially advantageous technique for treating HNCs, reducing dose to organs at risk (OARs) without jeopardizing tumour control, theoretically allowing a safe dose escalation. Proton therapy offers a dosimetric advantage over IMRT in the management of HNCs. While respecting dose constraints for normal tissues, IMPT is a promising technique for treatment-related toxicity reduction and potential dose escalation. In dosimetric comparisons, both techniques often sufficiently covered the target volume without issues. However, average minimum, maximum, and mean doses to the target volume are in general all higher for IMPT. Furthermore, IMPT appears to have an overall advantage in OAR doses in the brain stem, spinal cord, optic structures, cochlea, larynx, contralateral parotid and oral cavity with only a few exceptions. Dosimetric evidence of the superiority of IMPT compared to IMRT needs to be confirmed through evidence based clinical advantages. Several clinical studies are currently underway to provide compelling evidence for the clinical benefit of IMPT in HNCs. While IMPT has been employed purely for dosimetric properties, CIRT offers similar favourable physical characteristics, as well as an additional radiobiological advantage for radio-resistant tumours, such as salivary glands HNCs, malignant mucosal melanomas and sarcomas.

Salivary gland tumours (SGTs) are uncommon diseases that represent about $<1 \%$ of the all HNCs diagnosed in Europe. They arise either in the major or minor salivary glands, which are both located in the head and neck and include $>20$ histotypes [80,81]. SGTs have a known radio-resistance as well as frequently horseshoe-shaped volume and proximity to radiosensitive normal structures. For resectable cases, the mainstay of treatment is complete surgical resection with adequate free margins. In high-risk patients with adverse prognostic factors, based on the pathology results (close/positive margins, high grade, T size, vascular/perineural invasion and lymph node involvement), postoperative radiotherapy (PORT) is recommended. Patients with unresectable or inoperable SGTs undergo radiation therapy (RT) alone. Among SGTs, adenoid cystic carcinoma (ACC) is characterized by a high frequency of local recurrence; in the literature, it is the most investigated histotype to be treated with particles.

For SGTs, Vischioni et al. [82] reported a retrospective study of 51 patients (pts) with inoperable recurrent SGTs retreated with CIRT. Acute toxicity was G1 in 19 pts (37.3\%), G2 in 19 pts (37.3\%) and G3 in 2 pts (3.9\%). The median follow-up time was 19 months. Twenty-one (41.2\%) patients had Stable Disease (SD) and 30 (58.8\%) tumour progression at the time of last follow-up. Furthermore, $9(18 \%)$ patients had G1 late toxicity (scored according to CTCAE), 19 (37\%) had G2 and 9 (17. 5\%) had G3. Two-year PFS and OS were $52.2 \%$ and $64 \%$, respectively.

SGTs are rare conditions that are difficult to manage; therefore, they need to be treated in referral high-volume centres with a strong multidisciplinary expertise. Both CIRT and PT have been shown to be effective and safe in SGTs, though possibly with different indications. In a setting of high-risk patients without macroscopic tumour after surgery and proximity to radiosensitive normal structures, PT might be considered, while CIRT might be used in most inoperable or operable, but locally advanced, cases. A body of compelling evidence shows that CIRT improves LC, OS and toxicity in patients diagnosed with adenoid cystic carcinoma (ACC) [83]. The definition of a tumour signature allowing to select CIRT vs. PT or IMRT is an open question. Given the high efficacy of CIRT at CNAO, multidisciplinary 
follow-up in high expertise centres with well-trained oncologists in particle therapy should be pursued for each patient.

\subsection{Malignant Mucosal Melanoma}

Malignant mucosal melanomas (MM) are extremely rare and aggressive cancers. Compared to cutaneous melanomas, MM show different epidemiological and molecular features leading to unpredictable biological behaviour and worse prognosis. The incidence is very low, with an estimated annual rate of 1.5 per million in Europe [84]. Despite recent advances in treatment options, patients' survival remains very short, with a five-year OS rate of only $25 \%$ regardless of stage $[85,86]$. MM more frequently affect the upper aero-digestive tract, with the paranasal sinuses and nasal cavity as the most common sites. Among all melanomas, primary melanomas originating from the gynaecological tract are the rarest and really aggressive [87]. Head-and-neck mucosal melanoma (HNMM) comprise about $1 \%$ of all head-and-neck malignancies. Due to HNMM rarity and unpredictable clinical course, prospective studies are challenging, and to date no optimal treatment modality has been fully established. The mainstay of treatment for HNMM is surgery. Clear surgical margins are one of the most important prognostic factors [88-90], but are often difficult to obtain due to the anatomical complexity of the region and its proximity to vital structures.

Considering literature data, hadron therapy and CIRT in particular should be considered as a safe and effective treatment modality in curative setting for HNMM [91] and gynaecological $[92,93]$ patients not amenable to surgery. This is valid thanks to the dosimetrical advantage over conventional photon radiotherapy in case of strict proximity of organs at risk and to the radiobiological potential to overcome MM radio-resistance. This suggests that the addition of a systemic treatment to CIRT in a multimodal approach may improve patients' outcome, even though the contribution of concomitant chemotherapy was not confirmed in other Japanese studies [94]. Indeed, the major concern for HNMM is the mortality resulting from the propensity to metastasize early and widely.

Literature data and preliminary CNAO clinical results confirm that particle therapy, and in particular CIRT, is a safe and effective approach in the management of locally advanced HNMM. Preliminary data concerning the combination between Immune Checkpoint Inhibitors (ICIs) and CIRT appear promising in this setting [95]. These considerations lead to conclude that it is extremely important to manage patients considering CIRT in a multidisciplinary context in high expertise centres, in order to improve outcomes. Despite the good results in terms of LC and toxicity, overall survival remains poor, and prospective studies, preferably multi-centric, given the rarity of this disease, are needed to try to improve patients' outcomes.

\subsection{Clinical Research Trials}

Currently, CNAO is also performing clinical research and, for the following studies, the enrolment is ongoing:

1. PIOPPO (preoperative treatment of borderline operable pancreatic adenocarcinomas with chemotherapy and radiotherapy with carbon ions) [96]: a phase 2 study, to evaluate the neo-adjuvant combination approach with chemotherapy followed by short-course carbon-ion radiotherapy for borderline pancreatic adenocarcinomas [97];

2. CYCLE (carbon ion radiation therapy in the treatment of mucosal melanomas of the female lower genital tract): a phase 2 study to test the efficacy and the tolerability of carbon-ion treatments of unresectable gynaecological mucosal melanomas;

3. CYCLOPS (Phase II clinical study on the re-irradiation of lateral pelvic recurrences of gynecological malignancies) a phase 2 study, to evaluate the efficacy and tolerability of carbon-ion re-irradiation for not central relapses of gynaecological neoplasms at the edge of the previous photon beam radiotherapy; 
4. $4 \mathrm{D}-\mathrm{MRI}$ (guidance for organ motion management in particle treatments of thoracoabdominal tumours): a clinical trial to study the organ motion of thoraco-abdominal neoplasms through 4D MRI;

5. INSIDE: an experimental observational real-time live study of the particle range. This study is aimed at the early identification of potential morphological modifications of the target or of the adjacent areas, which might cause an anomaly in the dose distribution.

CNAO is also actively participating in the implementation of international clinical trials, such as:

1. STOPSTORM (a prospective European validation cohort for stereotactic therapy of Re-entrant tachycardia): aimed at the definition and harmonization of ventricular tachycardia radiation therapy treatment options (both medical and ablation therapy); to note that, at the end of 2019, in collaboration with Fondazione IRCSS Polyclinic San Matteo of Pave, for the first time in the literature, a patient affected by ventricular tachycardia (VT) has been successfully treated with proton beams at CNAO [98].

2. PROTECT (PROton versus photon Therapy for Esophageal Cancer-a Trimodality strategy): a randomized clinical study aimed at building scientific evidence (in terms of efficacy and toxicity) on the proton pre-op treatment, combined with chemotherapy, for oesophageal cancer. This clinical trial is then compared to the current gold standard treatment, which is a combination of chemotherapy and IMRT.

Moreover, CNAO is an active partner of ETOILE, an international randomized study, aiming to compare the carbon ion treatment to the traditional low-LET radiotherapy techniques (photons and protons) for radio-resistant histologies. In addition, it is involved in the randomized observational SACRO study, promoted by the Italian Sarcoma Group (ISG), that aims to compare upfront surgery to particle therapy in patients with sacral chordoma.

CNAO is also a partner, together with the Fondazione IRCSS Istituto Nazionale dei Tumori of Milan, of a prospective study promoted by the Istituto Europeo di Oncologia (Milan) and funded by AIRC (Italian Association of Cancer Research). The goal of this study is to evaluate the efficacy and toxicity of an early carbon ion boost, followed by Image Guided IG-IMRT for high-risk prostate cancers.

Lastly, CNAO is analysing the results of the two Italian multicentre phase 2 clinical studies SINTART1 and SINTART2, designed to primarily assess the efficacy of multimodality treatment (induction chemotherapy, surgery, photon and/or heavy ion radiotherapy) of patients with operable (SINTART1) and inoperable (SINTART2) sinonasal carcinoma.

A different model-based approach is worthwhile to mention as an alternative to clinical trials for hadron/proton therapy. The relationship between dose distribution and the risk of radiation-induced toxicity is described by NTCP [99]. Based on an in silico NTCP analysis on predicted toxicity between photons RT and proton therapy, Langendjik et al. [100] first suggested a step-wise RT methodology for selecting patients for proton therapy, accepted for the treatment refund by the Dutch health authorities. Moreover, this approach, known as model-based method, is implemented in the Netherlands to identify patients with head and neck cancer who may benefit most from proton therapy [101]. In brief, for each patient who may benefit from proton radiotherapy, a comparison between the most optimal photon and proton therapy plans were performed with the aim of estimating the NTCP profiles (considering the dose distribution and other clinical/treatment variables) for both techniques. The subtraction of photon-based from the proton-based NTCP $(\triangle N T C P)$ gives the probability of toxicity and patients are considered eligible for proton therapy if the model predicts less clinically relevant toxicity [102,103].

\section{Conclusions}

Hadron therapy is becoming more and more a clinical practice to treat in an efficient way an increasing number of pathologies. Proton centres are widely spread in the world and the threshold of 100 centres is going to be surpassed soon. Almost 300,000 patients have been treated with protons. The number of centres delivering carbon ions is still limited, 
due to the costs of the technology and infrastructures and only one dozen are presently in operation with almost 40,000 patients treated, but the future appears promising, thanks to the introduction of novel technologies that could reduce costs and dimensions.

The challenge of hadron therapy is to build clinical evidence. There is growing evidence for safety and effectiveness of particle therapy for a variety of clinical situations. However, there is still a lack of high-level evidence directly comparing proton therapy with modern conventional radiotherapy techniques. Some randomized trials comparing conventional radiation vs. proton therapy are underway (for low-grade glioma, oropharyngeal cancer and oesophageal cancer). For some pathologies such as chordomas, chondrosarcomas and salivary gland tumours, the carbon ions radiation therapy (CIRT) has proven to be highly effective. For many other tumour entities such as early-stage lung cancer, oesophageal cancer, hepatocellular carcinoma, pancreatic cancer, gynaecological tumours or prostate cancer, treatment with CIRT is being investigated, mainly through case series and few prospective studies. The major factor driving particle therapy implementation is the reduction in exit and integral dose compared to photon plans, resulting in a reduction in the dose to normal tissues. This should translate to reduced acute and long-term toxicity and improved post-therapy quality of life. The true impact of particle therapy on local tumour control (LC) or overall survival (OAS) can only be determined by clinical studies.

Research activities are important and necessary to fully exploit the hadron beams, both in terms of full control of the ballistic precision of hadrons, which is not at its full potential yet, and with respect to the radio-biological effectiveness of the therapeutic beams, which still requires systematic pre-clinical radiobiological experiments.

The Centre for Oncological Hadron therapy (CNAO) represents a centre of excellence, as a result of the initiative and the support of the Italian Ministry of Health and the Lombardy Region. More than 3700 patients have been treated with good results and many research activities are underway to improve the treatment outcome. New modalities are going to be introduced in the near future, namely a new single room for proton therapy with a gantry, a third ion source to have available new ion species for research and clinical applications, a new accelerator to produce neutron beams to activate the Boron Neutron Capture Therapy (BNCT) modality.

The personnel of CNAO represents the most important asset of the organization. To date, CNAO staff counts 154 members. The gender presence is close to $50-50$ [104,105]. The distinctive features of the staff are the young average age (40 years), the high level of education (79\% university graduates, 39\% with specializations and/or doctorates) and a considerable level of specialization (around twenty different organizational positions, held by individuals with a dozen different disciplinary backgrounds).

Prospectively, the creation of networks among hadron therapy facilities and conventional hospitals, research clinics, universities and research institutions is fundamental. These networks on one side can guarantee the growth of the cultural knowledge of hadron therapy, on the other side favour the efficient recruitment of the patients and last, but not least, make available the necessary competences for R\&D (Research ans Development) programmes.

Funding: The research activities at CNAO and at the other ion therapy facilities in EU are partly supported by the European Union's Horizon 2020 research and innovation programme under grant agreement N. 101008548 (HITRIplus).

Acknowledgments: The author wishes to thank Ugo Amaldi, Amelia Barcellini, Guido Baroni, Maria Di Rosa, Angelica Facoetti, Elisa Fiorina, Pierre Loap, Anna Mackova, Chiara Marazzi, Silvia Molinelli, Ester Orlandi, Marco Pullia and Arianna Serra for their contributions and help in writing this paper. The author is also deeply grateful to all the Staff of CNAO and of the collaborating institutions that are working to the development of the CNAO projects.

Conflicts of Interest: The author declares no conflict of interest. 


\section{References}

1. Haberer, T. Ion Beam Therapy at HIT: Options for Multi-Ion Treatment and Research. In Talk at the 3rd HITRIplus Seminar; Heidelberg University Hospital: Heidelberg, Germany, 13 October 2021. Available online: https://indico.cern.ch/event/1081649/ (accessed on 30 November 2021).

2. Krämer, K.; Durante, M. Ion beam transport calculations and treatment plans in particle therapy. Eur. Phys. J. 2010, 60, 195-202. [CrossRef]

3. Suit, H.; DeLaney, T.; Goldberg, S.; Paganetti, H.; Clasie, B.; Gerweck, L.; Niemierko, A.; Hall, E.; Flanz, J.; Hallman, J.; et al. Proton vs carbon ion beams in the definitive radiation treatment of cancer patients. Radiother. Oncol. 2010, 95, 3-22. [CrossRef] [PubMed]

4. Durante, M.; Loeffler, J.S. Charged particles in radiation oncology. Pub. Med. 2009, 7, 37-43. [CrossRef] [PubMed]

5. Averbeck, N.B.; Topsch, J.; Scholz, M.; Kraft-Weyrather, W.; Durante, M.; Taucher-Scholz, G. Efficient Rejoining of DNA Doublestrand breaks despite increased cell-killing effectiveness following spread-out bragg peak carbon-ion irradiation. Front. Oncol. 2016, 6, 1-8. [CrossRef]

6. Chiblak, S.; Tang, Z.; Campos, B.; Gal, Z.; Unterberg, A.; Debus, J.; Herold-Mendel, C.; Abdollahi, A. Radiosensitivity of patient-derived glioma stem cell 3-dimensional cultures to photon, proton, and carbon irradiation. Int. J. Radiat. Oncol. Biol. Phys. 2016, 95, 112-119. [CrossRef]

7. Peschke, P.; Debus, J. Relative biological effectiveness of carbon ions for local tumor control of a radioresistant prostate carcinoma in the rat. Int. J. Radiat. Oncol. Biol Phys. 2011, 79, 239-246. [CrossRef]

8. Debus, J.; Abdollahi, A. For the next trick: New discoveries in radiobiology applied to glioblastoma. Am. Soc. Clin. Oncol. Educ. Book 2014, 34, e95-e99. [CrossRef]

9. Klein, C.; Dokic, I.; Mairani, A.; Mein, S.; Brons, S.; Haring, P.; Haberer, T.; Jakel, O.; Zimmerman, A.; Zenke, F.; et al. Overcoming hypoxia-induced tumor radiore-sistance in non-small cell lung cancer by tar-geting DNA-dependent protein kinase in combination with carbon ion irradiation. Radiat. Oncol. 2017, 12, 208. [CrossRef]

10. Takahashi, Y.; Teshima, T.; Kawaguchi, N.; Hamada, Y.; Mori, S.; Madachi, A.; Ikeda, S.; Mizuno, H.; Ogata, T.; Nojima, K.; et al Heavy ion irradiation inhibits in vitro angiogenesis even at sublethal dose. Cancer Res. 2003, 63, 4253-4257.

11. Kamlah, F.; Hänze, J.; Arenz, A.; Seay, U.; Hasan, D.; Juricko, J.; Bischoff, B.; Gottschald, O.R.; Fournier, C.; Taucher-Scholz, G.; et al. Comparison of the effects of carbon ion and photon irradiation on the angiogenic response in human lung adenocarcinoma cells. Int. J. Radiat. Oncol. Biol. Phys. 2011, 80, 1541-1549. [CrossRef]

12. Ogata, T.; Teshima, T.; Kagawa, K.; Teshima, T.; Kagawa, K.; Hishikawa, Y.; Takahashi, Y.; Kawaguchi, A.; Suzumoto, Y.; Nojima, K.; et al. Particle irradiation suppresses metastatic potential of cancer cells. Cancer Res. 2005, 65, 113-120. [PubMed]

13. Rieken, S.; Rieber, J.; Brons, S.; Rieber, J.; Brons, S.; Habermehl, D.; Rief, H.; Orschiedt, L.; Lindel, K.; Weber, K.J.; et al. Radiation-induced motility alterations in medulloblastoma cells. J. Radiat. Res. 2015, 56, 430-436. [CrossRef] [PubMed]

14. Durante, M.; Brenner, D.J.; Formenti, S.C. Does heavy ion therapy work through the immune system? Int. J. Radiat. Oncol. Biol. Phys. 2016, 96, 934-936. [CrossRef] [PubMed]

15. Wilson, R.R. Radiological use of fast protons. Radiology 1946, 47, 487-491. [CrossRef]

16. Slater, J.M.; Archambeau, J.O.; Dicello, J.F.; Slate, J.D. Proton beam irradiation: Toward routin clinical utilization. In Hadrontherapy in Oncology: Proceedings of the First International Symposium on Hadrontherapy, Como, Italy, 18-21 October 1993; Amaldi, U., Larsson, B., Eds.; Elsevier Science: Amsterdam, The Netherland, 1994; p. 130.

17. Kawachi, K.; Yamada, S.; Sato, K.; Ogawa, H.; Soga, F.; Kanai, T.; Endo, M.; Hirao, Y. Heavy ion medical accelerator facility in Japan. In Hadrontherapy in Oncology: Proceedings of the First International Symposium on Hadrontherapy, Como, Italy, 18-21 October 1993; Amaldi, U., Larsson, B., Eds.; Elsevier Science: Amsterdam, The Netherlands, 1994; p. 229.

18. ENLIGHT. ENLIGHT Coordination. Available online: https:/ / enlight.web.cern.ch/enlight (accessed on 30 November 2021).

19. An Organization for Those Interested in Proton, Light Ion and Heavy Charged Particle Radiotherapy. Particle Therapy CoOperative Group. Available online: www.ptcog.ch (accessed on 30 November 2021).

20. NIMMS-Next Ion Medical Machine Study. CERN. Available online: https://kt.cern/kt-fund/projects/nimms-next-ion-medicalmachine-study (accessed on 30 November 2021).

21. CERN. I.FAST. Available online: https:/ / ifast-project.eu/home (accessed on 30 November 2021).

22. Mizushima, K.; Shirai, T.; Iwata, Y.; Furukawa, T.; Noda, K. Design of a Superconducting Synchrotron for Heavy-Ion Radiotherapy. In Proceedings of the 14th Annual Meeting of Particle Accelerator Society of Japan, Sapporo, Japan, 1-3 August 2017; pp. 1243-1245. Available online: https://www.pasj.jp/web_publish/pasj2017/proceedings/PDF/WEP1/WEP131.pdf (accessed on 30 November 2021). (In Japanese)

23. Benedetto, E.; Harbi, N.A.; Brouwer, L.; Tommasini, D.; Prestemon, S.; Riboni, P.; Amaldi, U. A carbon ion superconducting gantry and a synchrotron based on canted cosine-theta magnets. arXiv 2021, arXiv:2105.04205.

24. Amaldi, U.; Alharbi, N.; Benedetto, E.; Riboni, P.; Vaziri, M.; Aguglia, D.; Ferrentino, V.; Le Godec, G.; Karppinen, M.; Perini, D.; et al. SIGRUM-A Superconducting Ion Gantry with Riboni's Unconventional Mechamiics. CERN-ACC-NOTE-20210014 and NIMMS-Note-002. Available online: https:/ / cds.cern.ch/record/2766876 (accessed on 30 November 2021).

25. Badano, L.; Benedikt, M.; Bryant, P.J.; Crescenti, M.; Holy, P.; Maier, A.T.; Pullia, M.; Rossi, S.; Knaus, P. Proton-Ion Medical Machine Study (PIMMS). Part I; Report CERN/PS 99-010 (DI); CERN: Geneva, Switzerland, 1999. Available online: https: / / cds.cern.ch/record/385378 (accessed on 30 November 2021). 
26. Bryant, P.J.; Badano, L.; Benedikt, M.; Crescenti, M.; Holy, P.; Maier, A.T.; Pullia, M.; Reimoser, S.; Rossi, S.; Borri, G.; et al. Proton-Ion Medical Machine Study (PIMMS). Part II; Report CERN/PS 2000-007 (DR); CERN: Geneva, Switzerland, 2000. Available online: https:/ / cds.cern.ch/record/449577 (accessed on 30 November 2021).

27. Amaldi, U.; Magrin, G. (Eds.) The Path to the Italian National Centre for Ion Therapy; Edizioni Mercurio: Vercelli, Italy, 2005.

28. Rossi, S. The status of CNAO. Eur. Phys. J. Plus 2011, 126, 78. [CrossRef]

29. Fattori, G.; Riboldi, M.; Pella, A.; Peroni, M.; Cerveri, P.; Desplanques, M.; Fontana, G.; Tagaste, B.; Valvo, F.; Orecchia, R.; et al. Image guided particle therapy in CNAO room 2: Implementation and clinical validation. Phys. Med. 2015, 31, 9-15. [CrossRef]

30. Fattori, G.; Seregni, M.; Pella, A.; Riboldi, M.; Capasso, L.; Donetti, M.; Ciocca, M.; Giordanengo, S.; Pullia, M.; Marchetto, F.; et al. Real-time optical tracking for motion compensated irradiation with scanned particle beams at CNAO. Nucl. Instrum. Meth. Phys. Res. A Accel. Spectrom. Detect. Assoc. Equip. 2016, 827, 39-45. [CrossRef]

31. Via, R.; Fassi, A.; Fattori, G.; Fontana, G.; Pella, A.; Tagaste, B.; Riboldi, M.; Ciocca, M.; Orecchia, R.; Baroni, G. Optical eye tracking system for real-time noninvasive tumor localization in external beam radiotherapy. Med. Phys. 2015, 42, 2194-2202. [CrossRef]

32. Seregni, M.; Paganelli, C.; Summers, P.; Bellomi, M.; Baroni, G.; Riboldi, M. A hybrid image registration and matching framework for real-time motion tracking in MRI-guided radiotherapy. IEEE Trans. Biomed. Eng. 2018, 65, 131-139. [CrossRef]

33. Radiation Therapy. LEO Cancer Care. Available online: www.leocancercare.com (accessed on 30 November 2021).

34. Molinelli, S.; Magro, G.; Mairani, A.; Matsufuji, N.; Kanematsu, N.; Inaniwa, T.; Mirandola, A.; Russo, S.; Mastella, E.; Hasegawa, A.; et al. Dose prescription in carbon ion radiotherapy: How to compare two different RBE-weighted dose calculation systems. Radiother. Oncol. 2016, 120, 307-312. [CrossRef] [PubMed]

35. Fossati, P.; Molinelli, S.; Matsufuji, N.; Ciocca, M.; Mirandola, A.; Mairani, A.; Mizoe, J.; Hasegawa, A.; Imai, R.; Kamada, T.; et al. Dose prescription in carbon ion radiotherapy: A planning study to compare NIRS and LEM approaches with a clinically-oriented strategy. Phys. Med. Biol. 2012, 57, 7543-7554. [CrossRef] [PubMed]

36. Meschini, G.; Seregni, M.; Pella, A.; Ciocca, M.; Fossati, P.; Valvo, F.; Riboldi, M.; Baroni, G. Evaluation of residual abdominal tumour motion in carbon ion gated treatments through respiratory motion modelling. Phys. Med. 2017, 34, 28-37. [CrossRef] [PubMed]

37. Ciocca, M.; Mirandola, A.; Molinelli, S.; Russo, S.; Mastella, E.; Vai, A.; Mairani, A.; Magro, G.; Pella, A.; Donetti, M.; et al. Commissioning of the 4-D treatment delivery system for organ motion management in synchrotron-based scanning ion beams. Phys. Med. 2016, 32, 1667-1671. [CrossRef] [PubMed]

38. Meschini, G.; Paganelli, C.; Vai, A.; Fontana, G.; Molinelli, S.; Pella, A.; Vitolo, V.; Barcellini, A.; Orlandi, E.; Ciocca, M.; et al An MRI framework for respiratory motion modelling validation. J. Med. Imaging Radiat. Oncol. 2021, 65, 337-344. [CrossRef] [PubMed]

39. PANTECHNIK. ECR ION SOURCES. Available online: https://www.pantechnik.com/ecr-ion-sources/ (accessed on 30 November 2021).

40. Hub Research and Innovation, POR FESR 2014-2020, ID 1161908. Available online: https://home.infn.it/en/media-outreach/ infn-newsletter / newsletter-interview / 4680-interview-valerio-vercesi-2 (accessed on 30 November 2021).

41. Celona, L.; Ciavola, G.; Gammino, S.; Andò, L.; Mascali, D. Design of the AISHA Ion Source for Hadrontherapy Facilities. In Proceedings of the 20th International Workshop on ECR Ion Sources, ECRIS2012, Sydney, Australia, 25-28 September 2012; pp. 54-56. Available online: https:/ / accelconf.web.cern.ch/ECRIS2012/papers/tupp08.pdf (accessed on 30 November 2021).

42. Bisogni, M.G. The INSIDE bimodal system for range monitoring in particle therapy toward clinical validation. Nucl. Instrum. Meth. Phys. Res. A Accel. Spectrom. Detect. Assoc. Equip. 2019, 936, 73-74. [CrossRef]

43. Traini, G.; Mattei, I.; Battistoni, G.; Bisogni, M.; De Simoni, M.; Dong, Y.; Embriaco, A.; Fischetti, M.; Magi, M.; Mancini-Terracciano, C.; et al. Review and performance of the Dose Profiler, a particle therapy treatments online monitor. Phys. Med. 2019, 65, 84-93. [CrossRef]

44. Ferrero, V.; Fiorina, E.; Morrocchi, M.; Pennazio, F.; Baroni, G.; Battistoni, G.; Belcari, N.; Camarlinghi, N.; Ciocca, M.; del Guerra, A.; et al. Online proton therapy monitoring: Clinical test of a Silicon-photodetectorbased in-beam PET. Sci. Rep. 2018, 8, 4100. [CrossRef]

45. Fiorina, E.; Ferrero, V.; Pennazio, F.; Baroni, G.; Battistoni, G.; Belcari, N.; Cerello, P.; Camarlinghi, N.; Ciocca, M.; Del Guerra, A.; et al. Monte Carlo simulation tool for online treatment monitoring in hadrontherapy with in-beam PET: A patient study. Phys. Med. 2018, 51, 71-80. [CrossRef]

46. ClinicalTrials.gov. The U.S. National Library of Medicine. ID: NCT03662373. Available online: https://ClinicalTrials.gov (accessed on 30 November 2021).

47. Fiorina, E.; Ferrero, V.; Baroni, G.; Battistoni, G.; Belcari, N.; Camarlinghi, N.; Cerello, P.; Ciocca, M.; De Simoni, M.; Donetti, M.; et al. Detection of interfractional morphological changes in proton therapy: A simulation and in vivo study with the INSIDE in-beam PET. Front. Phys. 2021, 8, 660. [CrossRef]

48. Kraan, A.C.; Berti, A.; Retico, A.; Baroni, G.; Battistoni, G.; Belcari, N.; Cerello, P.; Ciocca, M.; de Simoni, M.; del Sarto, D.; et al. Localization of anatomical changes in patients during proton theraphy with in-beam PET monitoring: A Voxel Based Morphometry approach exploiting Monte Carlo simulations. Med. Phys. 2022, 49, 23-40. [CrossRef] [PubMed] 
49. Fischetti; Baroni, G.; Battistoni, G.; Bisogni, G.; Cerello, P.; Ciocca, M.; de Maria, P.; de Simoni, M.; di Lullo, B.; Donetti, M.; et al. Inter-fractional monitoring of ${ }^{12} \mathrm{C}$ ions treatments: Results from a clinical trial at the CNAO facility. Sci. Rep. 2020, 10, 20735. [CrossRef] [PubMed]

50. Toppi, M.; Baroni, G.; Battistoni, G.; Bisogni, M.G.; Cerello, P.; Ciocca, M.; De Maria, P.; De Simoni, M.; Donetti, M.; Dong, Y.; et al. Monitoring carbon ion beams transverse position detecting charged secondary fragments: Results from patient treatment performed at CNAO. Front. Oncol. 2021, 11, 601784. [CrossRef] [PubMed]

51. Lis, M.; Newhauser, W.; Donetti, M.; Wolf, M.; Steinsberger, T.; Paz, A.; Graeff, C. Preliminary tests of dosimetric quality and projected therapeutic outcomes of multi-phase 4D radiotherapy with proton and carbon ion beams. Phys. Med. Biol. 2021, 66, 23. [CrossRef]

52. Favaudon, V.; Caplier, L.; Monceau, V.; Pouzoulet, F.; Sayarath, M.; Fouillade, C.; Poupon, M.-F.; Brito, I.; Hupé, P.; Bourhis, J.; et al. Ultrahigh dose-rate FLASH irradiation increases the differential response between normal and tumor tissue in mice. Sci. Transl. Med. 2014, 6, 245ra93. [CrossRef]

53. Haberer, T.; Becher, W.; Schardt, D.; Kraft, G. Magnetic scanning system for heavy ion therapy. Nucl. Instrum. Meth. Phys. Res. A Accel. Spectrom. Detect. Assoc. Equip. 1993, 330, 296-305. [CrossRef]

54. Haberer, T.; Debus, J.; Eickhoff, H.; Jäkel, O.; Schulz-Ertner, D.; Weber, U. The Heidelberg Ion Therapy Center. Radiother. Oncol. 2004, 73 (Suppl. 2), S186-S190. [CrossRef]

55. Schoemers, C.; Feldmeier, E.; Galonska, M.; Haberer, T.; Horn, J.; Peters, A. First tests of a re-accelerated beam at Heidelberg Ion-Beam Therapy Centre (HIT). In Proceedings of the 8th International Particle Accelerator Conference, IPAC2017, Copenhagen, Denmark, 14-19 May 2017; pp. 4647-4649. Available online: https://accelconf.web.cern.ch/ipac2017/papers/thpva083.pdf (accessed on 30 November 2021).

56. Saverwein, W.; Wittig, A.; Moss, R.; Nakagawa, Y. Neutron Capture Therapy: Principles and Applications; Springer: Berlin/Heidelberg, Germany, 2012. [CrossRef]

57. Suzuki, M. Boron Neutron Capture Therapy (BNCT): A unique role in radiotherapy with a view to entering the accelerator-based BNCT era. Int. J. Clin. Oncol. 2020, 25, 43-50. [CrossRef]

58. Buizza, G.; Paganelli, C.; D'ippolito, E.; Fontana, G.; Molinelli, S.; Preda, L.; Riva, G.; Iannalfi, A.; Valvo, F.; Orlandi, E.; et al. Radiomics and dosiomics for predicting local control after carbon-ion radiotherapy in skull-base chordoma. Cancers 2021, 13, 339. [CrossRef]

59. Buizza, G.; Molinelli, S.; D’Ippolito, E.; Fontana, G.; Pella, A.; Valvo, F.; Preda, L.; Orecchia, R.; Baroni, G.; Paganelli, C. MRI-based tumour control probability in skull-base chordomas treated with carbon-ion therapy. Radiother. Oncol. 2019, 137, 32-37. [CrossRef]

60. Zampini, M.; Buizza, G.; Paganelli, C.; Fontana, G.; D’Ippolito, E.; Valvo, F.; Preda, L.; Baroni, G. Perfusion and diffusion in meningioma tumors: A preliminary multiparametric analysis with Dynamic Susceptibility Contrast and IntraVoxel Incoherent Motion MRI. Magn. Reson. Imaging 2020, 67, 69-78. [CrossRef] [PubMed]

61. Monti, S.; Paganelli, C.; Buizza, G.; Preda, L.; Valvo, F.; Baroni, G.; Palma, G.; Cella, L. A novel framework for spatial normalization of dose distributions in voxel-based analyses of brain irradiation outcomes. Phys. Med. 2020, 69, 164-169. [CrossRef] [PubMed]

62. Buizza, G.; Zampini, M.A.; Riva, G.; Molinelli, S.; Fontana, G.; Imparato, S.; Ciocca, M.; Iannalfi, A.; Orlandi, E.; Baroni, G.; et al. Investigating DWI changes in white matter of meningioma patients treated with proton therapy. Phys. Med. 2021, 84, 72-79. [CrossRef] [PubMed]

63. Buizza, G.; Paganelli, C.; Ballati, F.; Sacco, S.; Preda, L.; Iannalfi, A.; Alexander, D.C.; Baroni, G.; Palombo, M. Improving the characterization of meningioma microstructure in proton therapy from conventional apparent diffusion coefficient measurements using Monte Carlo simulations of diffusion MRI. Phys. Med. 2021, 48, 1250-1261. [CrossRef] [PubMed]

64. RaySearch Laboratories. ADVANCING CANCER TREATMENT. Available online: www.raysearchlabs.com (accessed on 30 November 2021).

65. Molinelli, S.; Russo, S.; Magro, G.; Maestri, D.; Mairani, A.; Mastella, E.; Mirandola, A.; Vai, A.; Vischioni, B.; Valvo, F.; et al. Impact of TPS calculation algorithms on dose delivered to the patient in proton therapy treatments. Phys. Med. Biol. 2019, 64, 075016. [CrossRef] [PubMed]

66. Molinelli, S.; Bonora, M.; Magro, G.; Casale, S.; Dale, J.E.; Fossati, P.; Hasegawa, A.; Mirandola, A.; Ronchi, S.; Russo, S.; et al. RBE-weighted dose in carbon ion therapy for ACC patients: Impact of the RBE model translation on treatment outcomes. Radiother. Oncol. 2019, 141, 227-233. [CrossRef]

67. Molinelli, S.; Magro, G.; Mairani, A.; Allajbej, A.; Mirandola, A.; Chalaszczyk, A.; Imparato, S.; Ciocca, M.; Fiore, M.R.; Orlandi, E. How LEM-based RBE and dose-averaged LET affected clinical outcomes of sacral chordoma patients treated with carbon ion radiotherapy. Radiother. Oncol. 2021, 163, 209-214. [CrossRef]

68. Russo, S.; Ricotti, R.; Molinelli, S.; Patti, F.; Barcellini, A.; Mastella, E.; Pella, A.; Paganelli, C.; Marvaso, G.; Pepa, M.; et al. Dosimetric impact of inter-fraction anatomical changes in carbon ion boost treatment for high-risk prostate cancer (AIRC IG 14300). Front. Oncol. 2021, 11, 740661. [CrossRef]

69. Meschini, G.; Vai, A.; Paganelli, C.; Molinelli, S.; Maestri, D.; Fontana, G.; Pella, A.; Vitolo, V.; Valvo, F.; Ciocca, M.; et al. Investigating the use of virtual 4DCT from 4DMRI in gated carbon ion radiation therapy of abdominal tumors. Med. Phys. 2020, in press. [CrossRef]

70. RAPTOR. ITN. Available online: https:/ / raptor-consortium.com (accessed on 30 November 2021). 
71. Loap, P.; Mirandola, A.; De Marzi, L.; Vitolo, V.; Barcellini, A.; Iannalfi, A.; Dendale, R.; Kirova, Y.; Orlandi, E. Cardiac conduction system exposure with modern radiotherapy techniques for mediastinal Hodgkin lymphoma irradiation. Acta Oncol. 2022, 1-4. [CrossRef]

72. Loeffler, J.S.; Durante, M. Charged particle therapy—optimization, challenges and future directions. Nat. Rev. Clin. Oncol. 2013, 10, 411-424. [CrossRef] [PubMed]

73. Fujita, M.; Yamada, S.; Imai, T. Irradiation induces diverse changes in invasive potential in cancer cell lines. Semin. Cancer Biol. 2015, 35, 45-52. [CrossRef] [PubMed]

74. Facoetti, A.; Di Gioia, C.; Pasi, F.; Di Liberto, R.; Corbella, F.; Nano, R.; Ciocca, M.; Valvo, F.; Orecchia, R. Morphological analysis of amoeboid-mesenchymal transition plasticity after low and high LET radiation on migrating and invading pancreatic cancer cells. Anticancer Res. 2018, 38, 4585-4591. [CrossRef] [PubMed]

75. Croce, S.; Peloso, A.; Zoro, T.; Avanzini, M.A.; Cobianchi, L. A Hepatic scaffold from decellularized liver tissue: Food for thought. Biomolecules 2019, 9, 813. [CrossRef] [PubMed]

76. Zhang, M.; Zhu, Z.-L.; Gao, X.-L.; Wu, J.-S.; Liang, X.-H.; Tang, Y.-L. Functions of chemokines in the perineural invasion of tumors (Review). Int. J. Oncol. 2018, 52, 1369-1379. [CrossRef] [PubMed]

77. Di Renzo, M.F.; Corso, S. Patient-derived cancer models. Cancers 2020, 12, 3779. [CrossRef] [PubMed]

78. Friedrich, T.; Henthorn, N.; Durante, M. Modeling radioimmune response-current status and perspectives. Front. Oncol. 2021, 11, 647272. [CrossRef]

79. Iannalfi, A.; D’Ippolito, E.; Riva, G.; Molinelli, S.; Gandini, S.; Viselner, G.; Fiore, M.R.; Vischioni, B.; Vitolo, V.; Bonora, M.; et al Proton and carbon ion radiotherapy in skull base chordomas: A prospective study based on a dual particle and a patientcustomized treatment strategy. Neurol. Oncol. 2020, 22, 1348-1358. [CrossRef]

80. Van Dijk, B.A.; Gatta, G.; Capocaccia, R.; Pierannunzio, D.; Strojan, P.; Licitra, L.; The RARECARE Working Group. Rare cancers of the head and neck area in Europe. Eur. J. Cancer 2012, 48, 783-796. [CrossRef]

81. El-Naggar, A.K.; Chan, J.F.K.; Grandis, J.R.; Takata, T.; Slootweg, P.J. WHO Classification of Head and Neck Tumours, 4th ed.; World Health Organization: Geneva, Switzerland, 2017; Volume 9.

82. Vischioni, B.; Dhanireddy, B.; Severo, C.; Bonora, M.; Ronchi, S.; Vitolo, V.; Fiore, M.R.; D’Ippolito, E.; Petrucci, R.; Barcellini, A.; et al. Reirradiation of salivary gland tumors with carbon ion radiotherapy at CNAO. Radiother. Oncol. 2020, 145, 172-177. [CrossRef]

83. Loap, P.; Vischioni, B.; Bonora, M.; Ingargiola, R.; Ronchi, S.; Vitolo, V.; Barcellini, A.; Goanta, L.; De Marzi, L.; Dendale, R.; et al. Biological rationale and clinical evidence of carbon ion radiation therapy for adenoid cystic carcinoma: A narrative review. Front. Oncol. 2021, 11, 789079. [CrossRef] [PubMed]

84. RARECAREnet. Information Network on Rare Cancers. 2017. Available online: http://www.rarecarenet.eu/rarecarenet/ (accessed on 30 November 2021).

85. Kirchoff, D.D.; Deutsch, G.B.; Foshag, L.J.; Lee, J.H.; Sim, M.-S.; Faries, M.B. Evolving therapeutic strategies in mucosal melanoma have notiImproved survival over five decades. Am. Surg. 2016, 82, 1-5. [CrossRef] [PubMed]

86. Teterycz, P.; Czarnecka, A.M.; Indini, A.; Spałek, M.J.; Labianca, A.; Rogala, P.; Cybulska-Stopa, B.; Quaglino, P.; Ricardi, U.; Badellino, S.; et al. Multimodal treatment of advanced mucosal melanoma in the era of modern immunotherapy. Cancers 2020, 12, 3131. [CrossRef] [PubMed]

87. Gadducci, A.; Carinelli, S.; Guerrieri, M.E.; Aletti, G.D. Melanoma of the lower genital tract: Prognostic factors and treatment modalities. Gynecol. Oncol. 2018, 150, 180-189. [CrossRef] [PubMed]

88. Penel, N.; Mallet, Y.; Mirabel, X.; Van, J.T.; Lefebvre, J.-L. Primary mucosal melanoma of head and neck: Prognostic value of clear margins. Laryngoscope 2006, 116, 993-995. [CrossRef]

89. Shuman, A.G.; Light, E.; Olsen, S.H.; Pynnonen, M.A.; Taylor, J.M.; Johnson, T.M.; Bradford, C.R. Mucosal melanoma of the head and neck: Predictors of prognosis. Arch. Otolaryngol. Head Neck Surg. 2011, 137, 331-337. [CrossRef]

90. Lee, S.P.; Shimizu, K.T.; Tran, L.M.; Juillard, G.; Calcaterra, T.C. Mucosal melanoma of the head and neck: The impact of local control on survival. Laryngoscope 1994, 104, 121-126. [CrossRef]

91. Ebner, D.K.; Malouff, T.D.; Frank, S.J.; Koto, M. The role of particle therapy in adenoid cystic carcinoma and mucosal melanoma of the head and neck. Int. J. Part Ther. 2021, 8, 273-284. [CrossRef]

92. Murata, H.; Okonogi, N.; Wakatsuki, M.; Kato, S.; Kiyohara, H.; Karasawa, K.; Ohno, T.; Nakano, T.; Kamada, T.; Shozu, M.; et al. Long-term outcomes of carbon-ion radiotherapy for malignant gynecological melanoma. Cancers 2019, 11, 482. [CrossRef]

93. Barcellini, A.; Vitolo, V.; Facoetti, A.; Fossati, P.; Preda, L.; Fiore, M.R.; Vischioni, B.; Iannalfi, A.; Bonora, M.; Ronchi, S.; et al. Feasibility of carbon ion radiotherapy in the treatment of gynecological melanoma. In Vivo 2019, 33, 473-476. [CrossRef]

94. Takayasu, Y.; Kubo, N.; Shino, M.; Nikkuni, O.; Ida, S.; Musha, A.; Takahashi, K.; Hirato, J.; Shirai, K.; Saitoh, J.; et al. Working Group on Head and Neck Tumors. Carbon-ion radiotherapy combined with chemotherapy for head and neck mucosal melanoma: Prospective observational study. Cancer Med. 2019, 8, 7227-7235. [CrossRef] [PubMed]

95. Cavalieri, S.; Ronchi, S.; Barcellini, A.; Bonora, M.; Vischioni, B.; Vitolo, V.; Villa, R.; Del Vecchio, M.; Licitra, L.; Orlandi, E. Toxicity of carbon ion radiotherapy and immune checkpoint inhibitors in advanced melanoma. Radiother. Oncol. 2021, 164, 1-5. [CrossRef] [PubMed]

96. ClinicalTrials.gov. The U.S. National Library of Medicine. ID: NCT03822936. Available online: https://ClinicalTrials.gov (accessed on 30 November 2021). 
97. Vitolo, V.; Cobianchi, L.; Brugnatelli, S.; Barcellini, A.; Peloso, A.; Facoetti, A.; Vanoli, A.; Delfanti, S.; Preda, L.; Molinelli, S.; et al. Preoperative chemotherapy and carbon ions therapy for treatment of resectable and borderline resectable pancreatic adenocarcinoma: A prospective, phase II, multicentre, single-arm study. BMC Cancer 2019, 19, 922. [CrossRef] [PubMed]

98. Dusi, V.; Vitolo, V.; Frigerio, L.; Totaro, R.; Valentini, A.; Barcellini, A.; Mirandola, A.; Perego, G.B.; Coccia, M.; Greco, A.; et al. First-in-man case of non-invasive proton radiotherapy for the treatment of refractory ventricular tachycardia in advanced heart failure. Eur. J. Heart Fail. 2020, 23, 195-196. [CrossRef] [PubMed]

99. Niemierko, A.; Goitein, M. Calculation of normal tissue complication probability and dose-volume histogram reduction schemes for tissues with a critical element architecture. Radiother. Oncol. 1991, 20, 166-176. [CrossRef]

100. Langendijk, J.A.; Lambin, P.; De Ruysscher, D.; Widder, J.; Bos, M.; Verheij, M. Selection of patients for radiotherapy with protons aiming at reduction of side effects: The model-based approach. Radiother. Oncol. 2013, 107, 267-273. [CrossRef]

101. Langendijk, J.A.; Hoebers, F.J.P.; de Jong, M.A.; Doornaert, P.; Terhaard, C.H.J.; Steenbakkers, R.J.H.M.; Hamming-Vrieze, O.; van de Kamer, J.B.; Verbakel, W.F.A.R.; Keskin-Cambay, F.; et al. National protocol for model-based selection for proton therapy in head and neck cancer. Int. J. Part Ther. 2021, 8, 354-365. [CrossRef]

102. Tambas, M.; Steenbakkers, R.J.H.M.; van der Laan, H.P.; Wolters, A.M.; Kierkels, R.G.J.; Scandurra, D.; Korevaar, E.W.; Oldehinkel, E.; van Zon-Meijer, T.W.H.; Both, S.; et al. First experience with model-based selection of head and neck cancer patients for proton therapy. Radiother. Oncol. 2020, 151, 206-213. [CrossRef]

103. Dionisi, F.; Widesott, L.; Van Vulpen, M.; Fuller, C.D.; Frondizi, R.; Meneguzzo, M.; Blanchard, P.; Amichetti, M.; Sanguineti, G. Methodologies to increase the level of evidence of real-life proton therapy in head and neck tumors. Int. J. Part Ther. 2021, 8, 328-338. [CrossRef]

104. Orlandi, E.; Dal Mas, F.; Paoloni, P.; Band, H.; Fiore, M.R.; Vischioni, B.; Vitolo, V.; Campo, C.; Facoetti, A.; Necchi, M.; et al. A short reflection on COVID-19 and gender equality in healthcare. In Organizational Resilience and Female Entrepreneurship During Crises. Emerging Evidence and Future Agenda; Paoloni, P., Lombardi, R., Eds.; Springer: Berlin/Heidelberg, Germany, 2022. [CrossRef]

105. Paoloni, P.; Dal Mas, F.; Massaro, M.; Barcellini, A.; Orlandi, E. An Organizational model for female leadership in healthcare. The National Centre of Oncological Hadrontherapy (CNAO Foundation) experience during the COVID-19 pandemic. In Proceedings of the 4th International Conference on Gender Research, ICGR 2021, Aveiro, Portugal, 21-22 June 2021; Pereira, E.T., Costa, C., Breda, Z., Eds.; Academic Conferences and Publishing International Limited: Reading, UK, 2021; pp. 228-237. [CrossRef] 